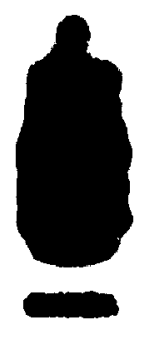

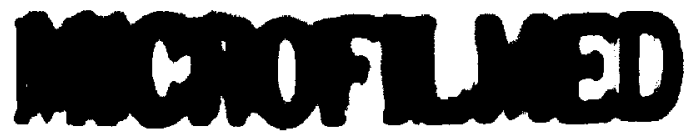

D

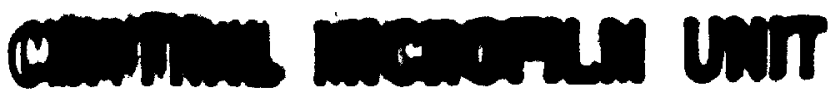

PUIC Nichives

or

CANADA

OIIThm, cortabio
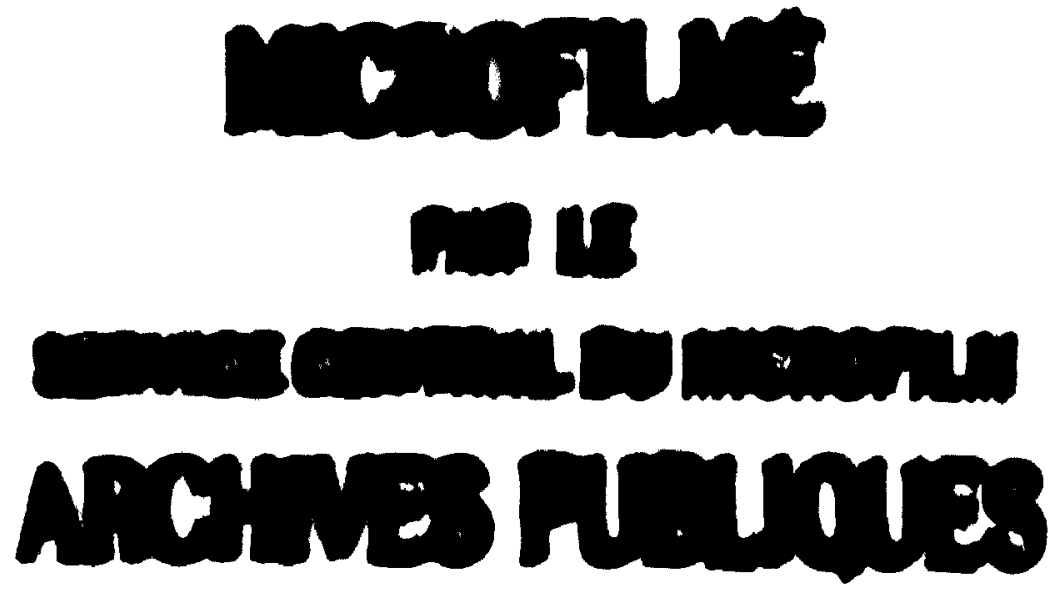

r

CMnT

1,1

15

opearrale $4=93$ 


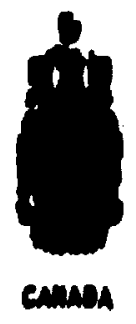

NATIONAL LIBRARY

OF CANADA

BIBLIOTHËQUE

NATIONALE

CANADIAN THESES

DU CANADA

ON MICROFILM

THËSES CANADIENNES

SUR MICROFILM

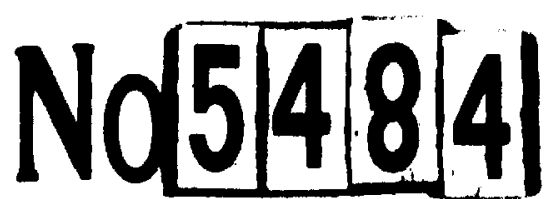



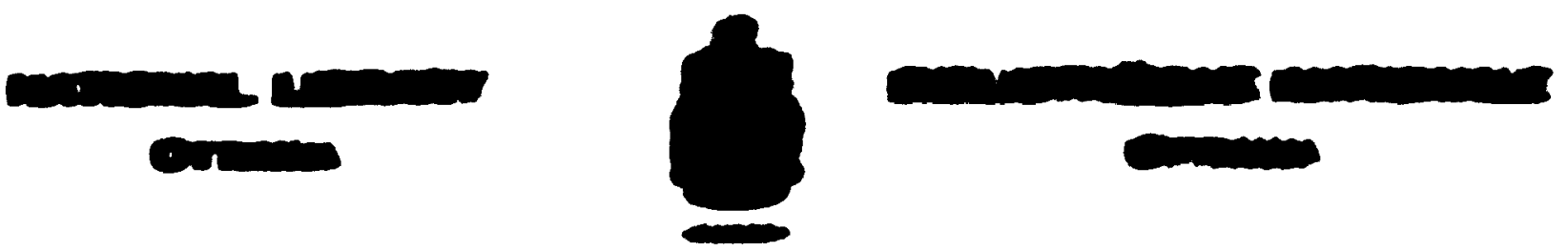

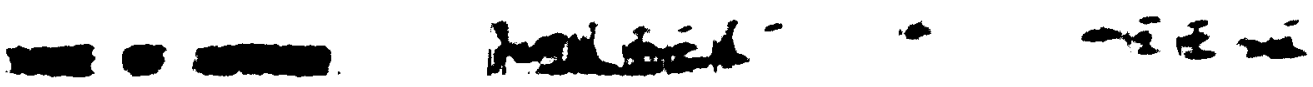

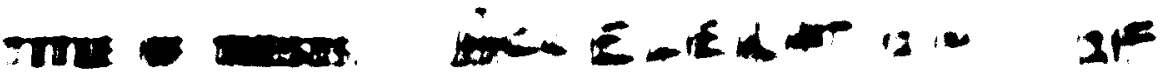

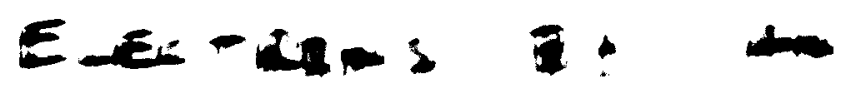

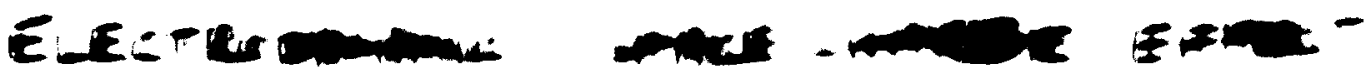

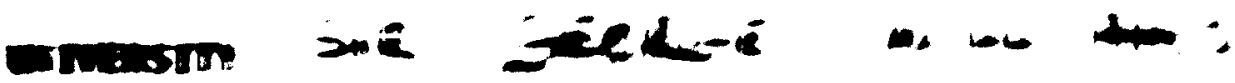

wa

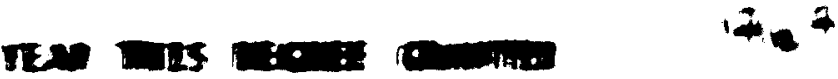

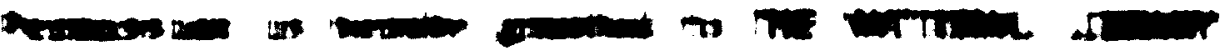

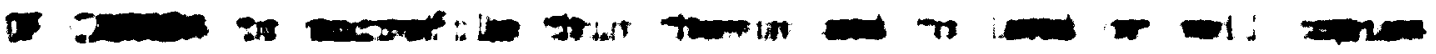

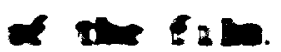

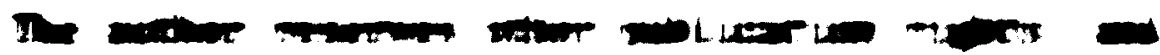

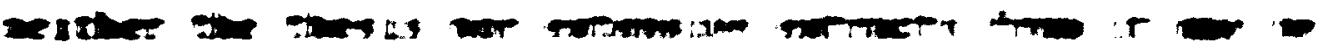

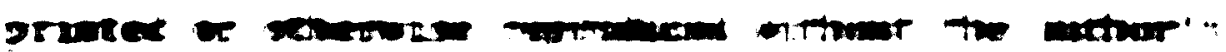

oritsen srimess de

$$
340-6-1 \text { in } x=
$$

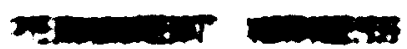$$
\rightarrow: \text { - }
$$

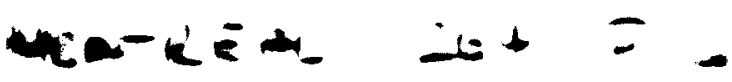

OATED Sipt U : $c^{7}$ 


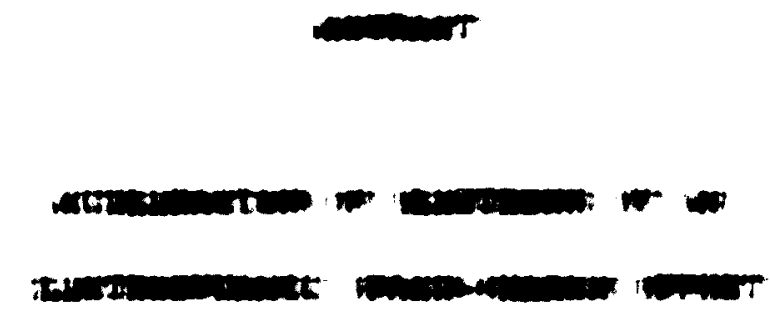

10

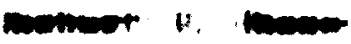

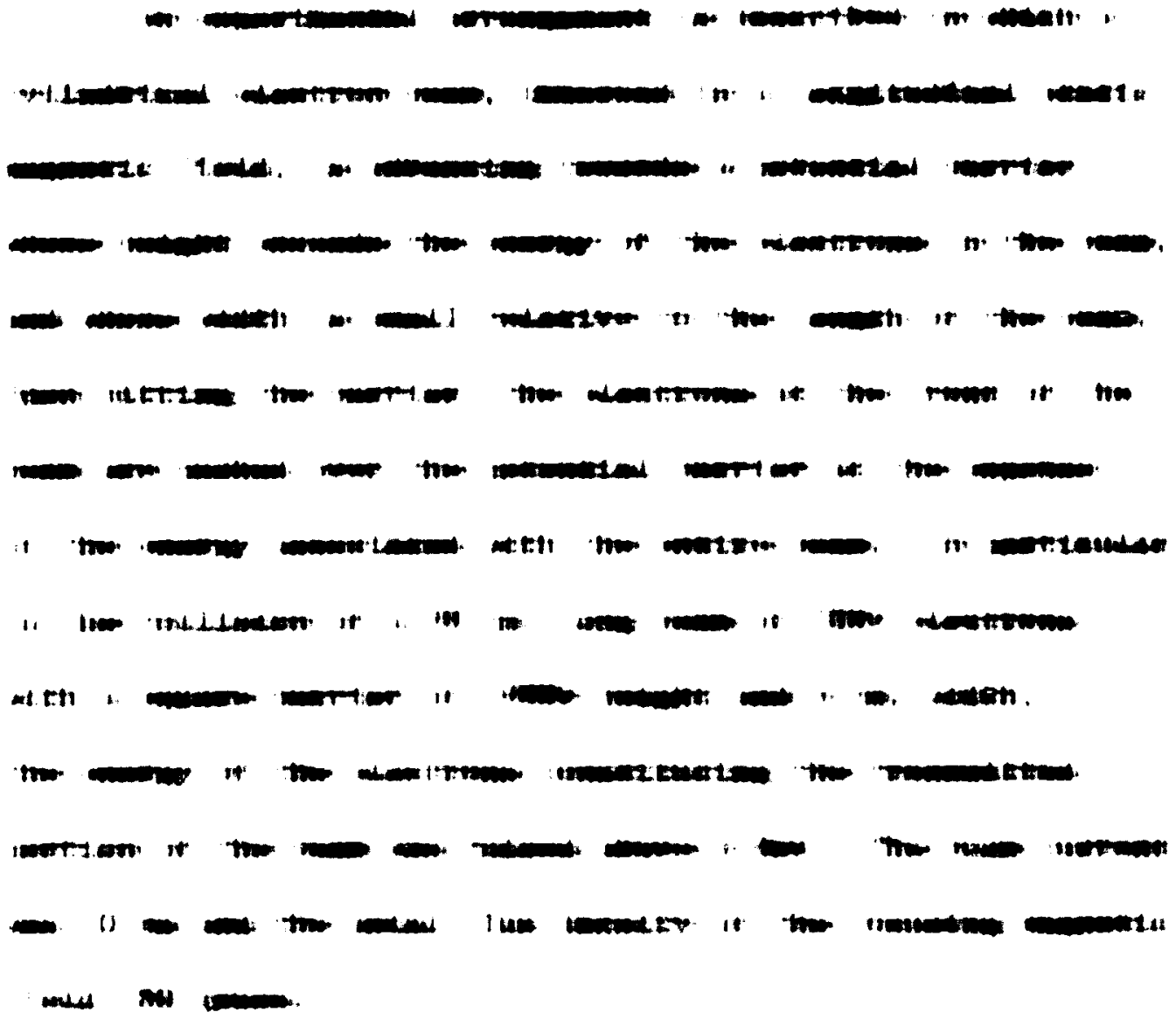




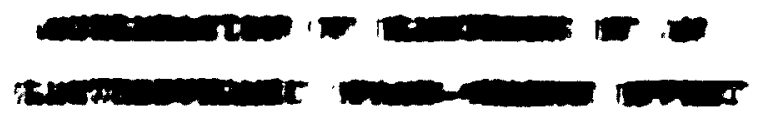

1.

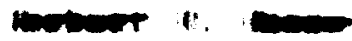

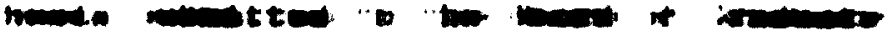

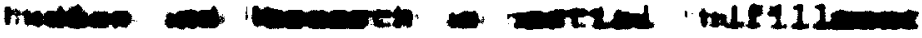

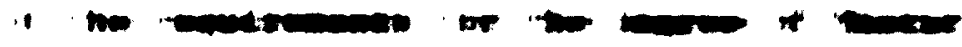
1 1010
}

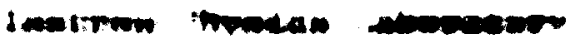

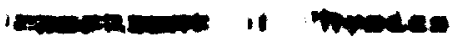

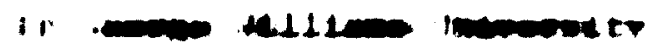

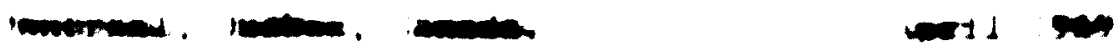




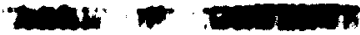

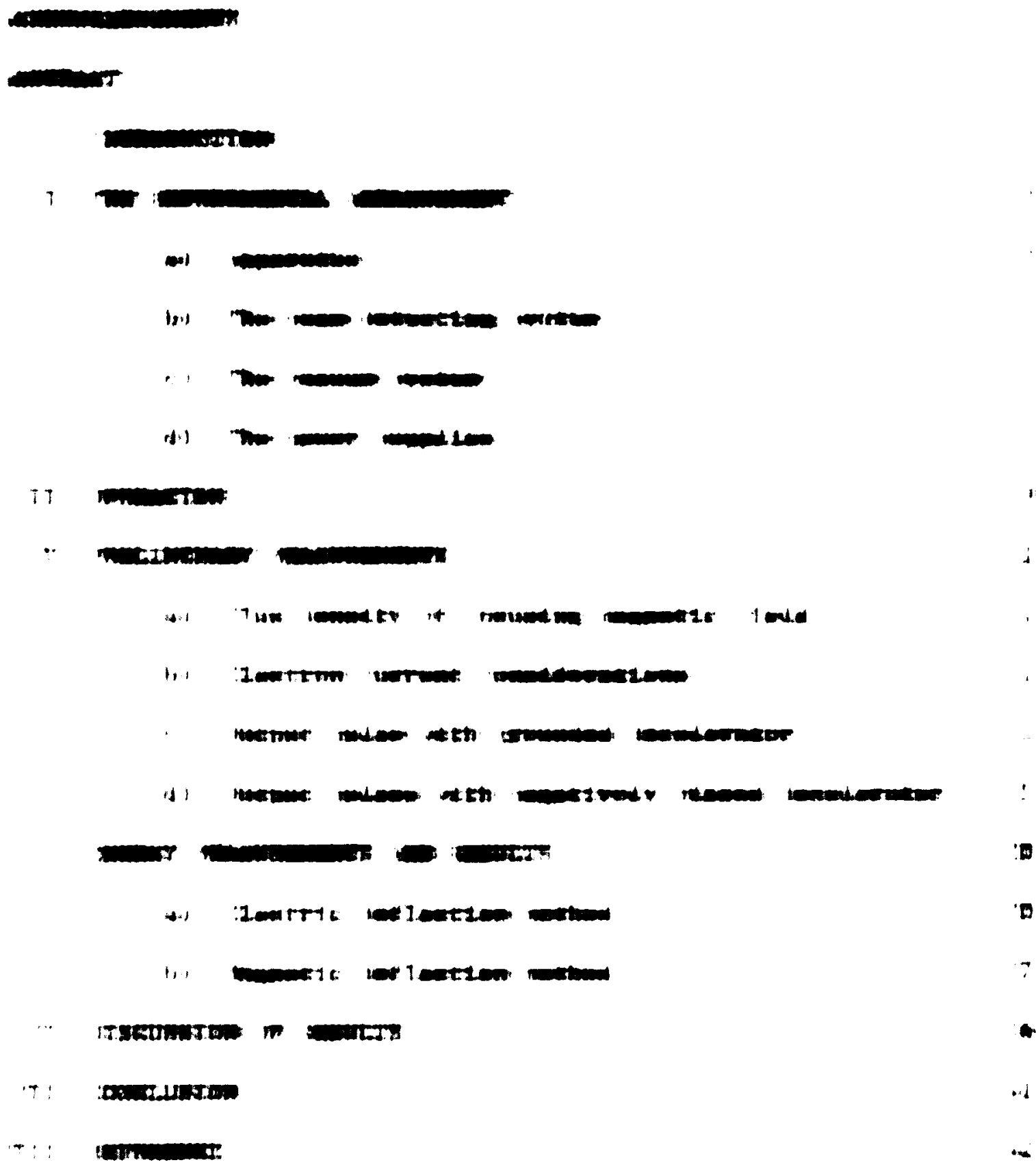




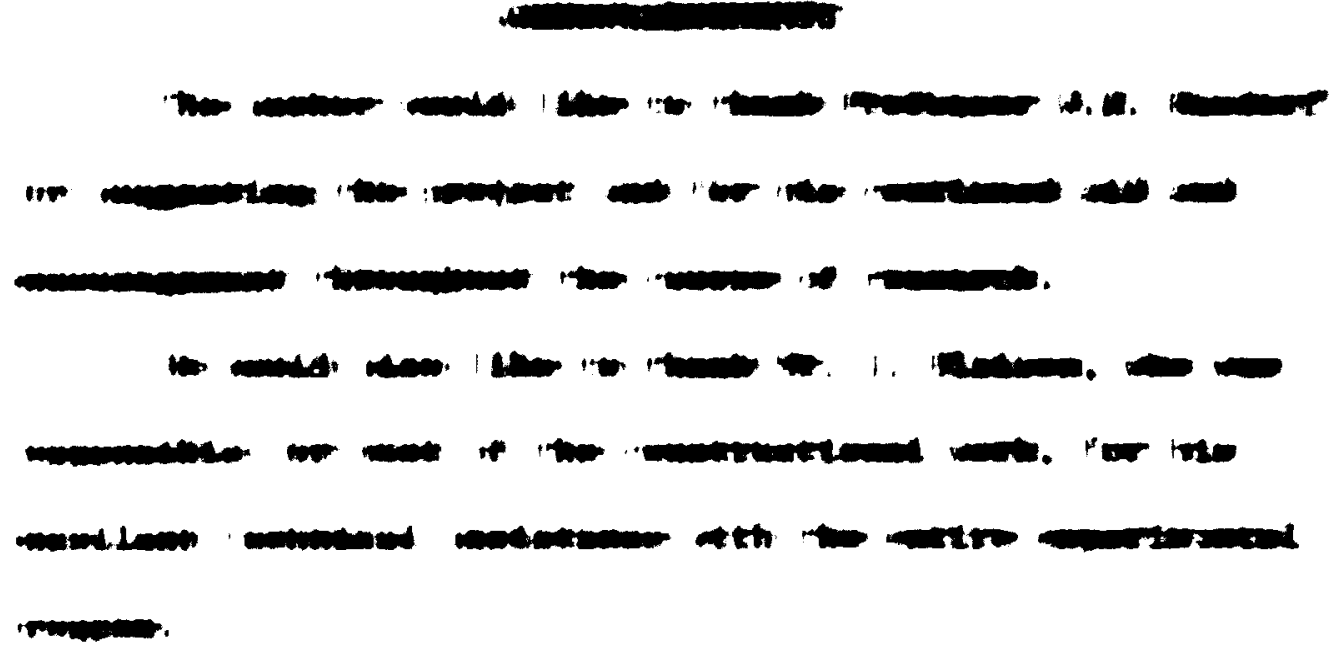




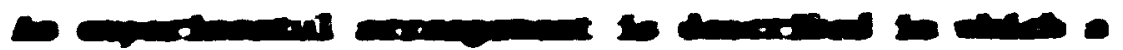

G)

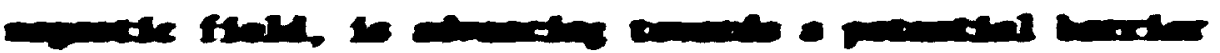

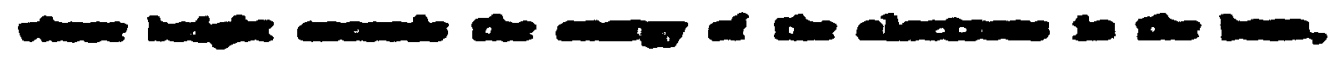

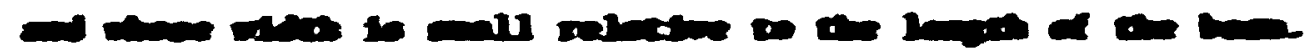

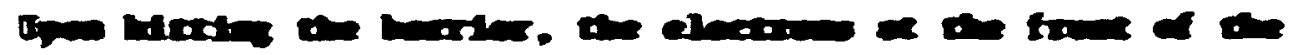

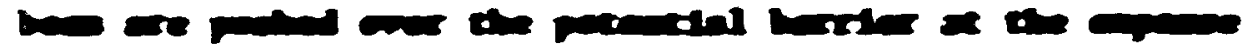

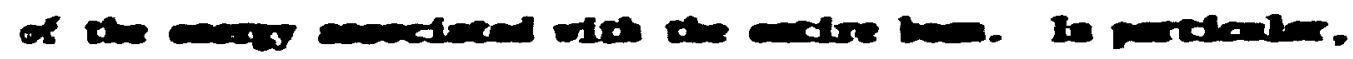

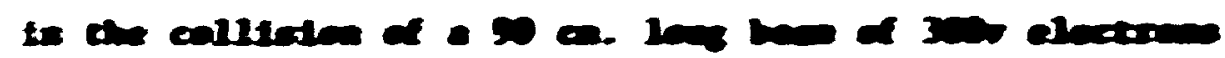

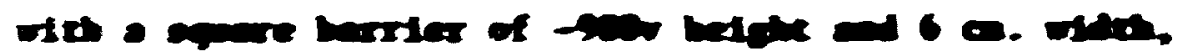

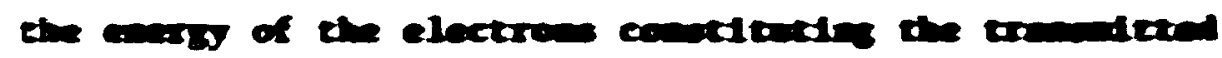

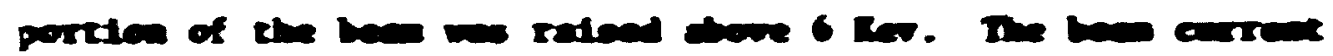

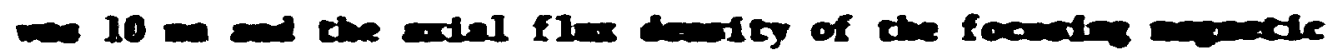

Etelt 240 


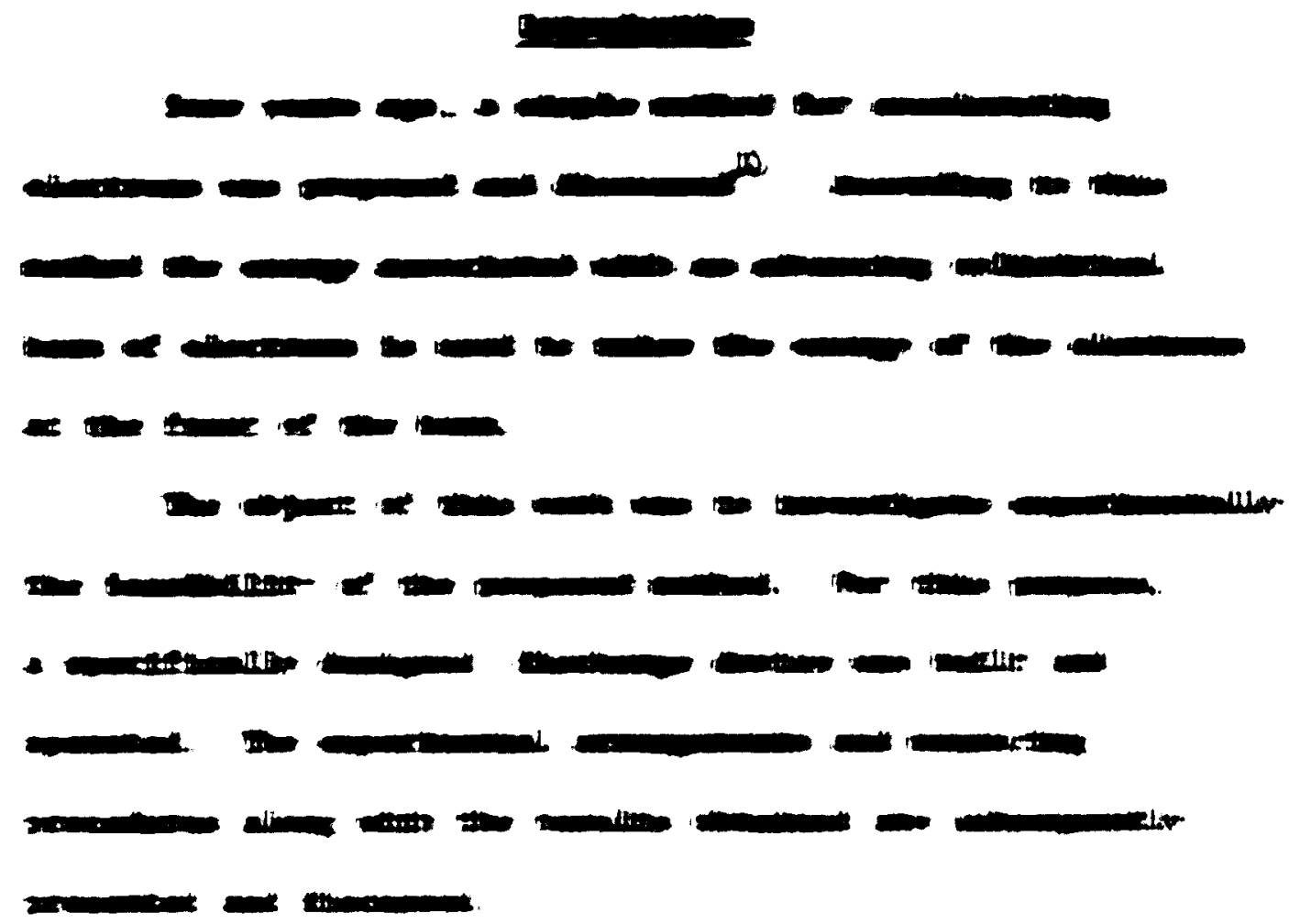




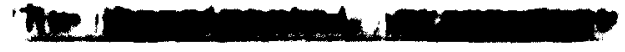

4

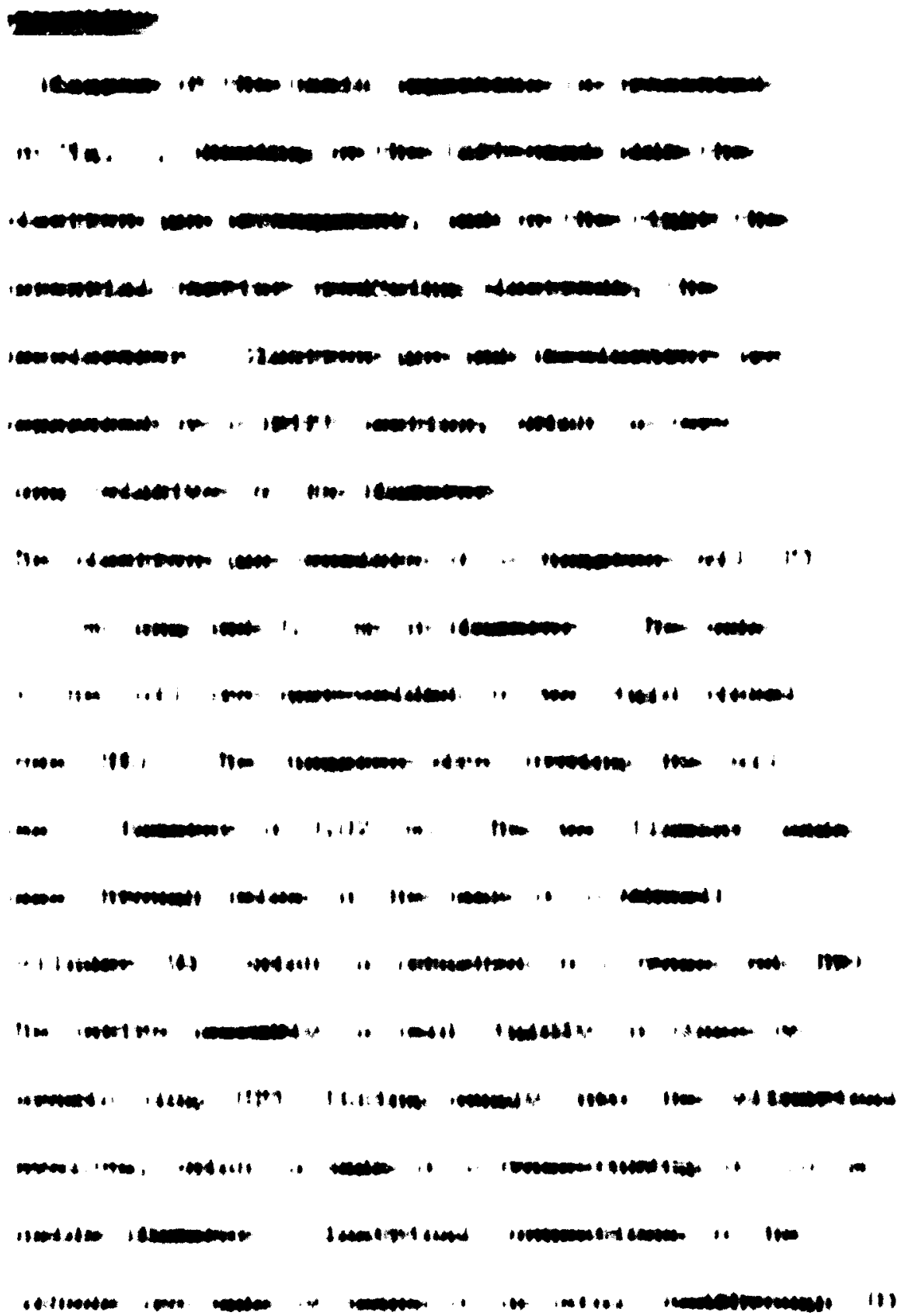




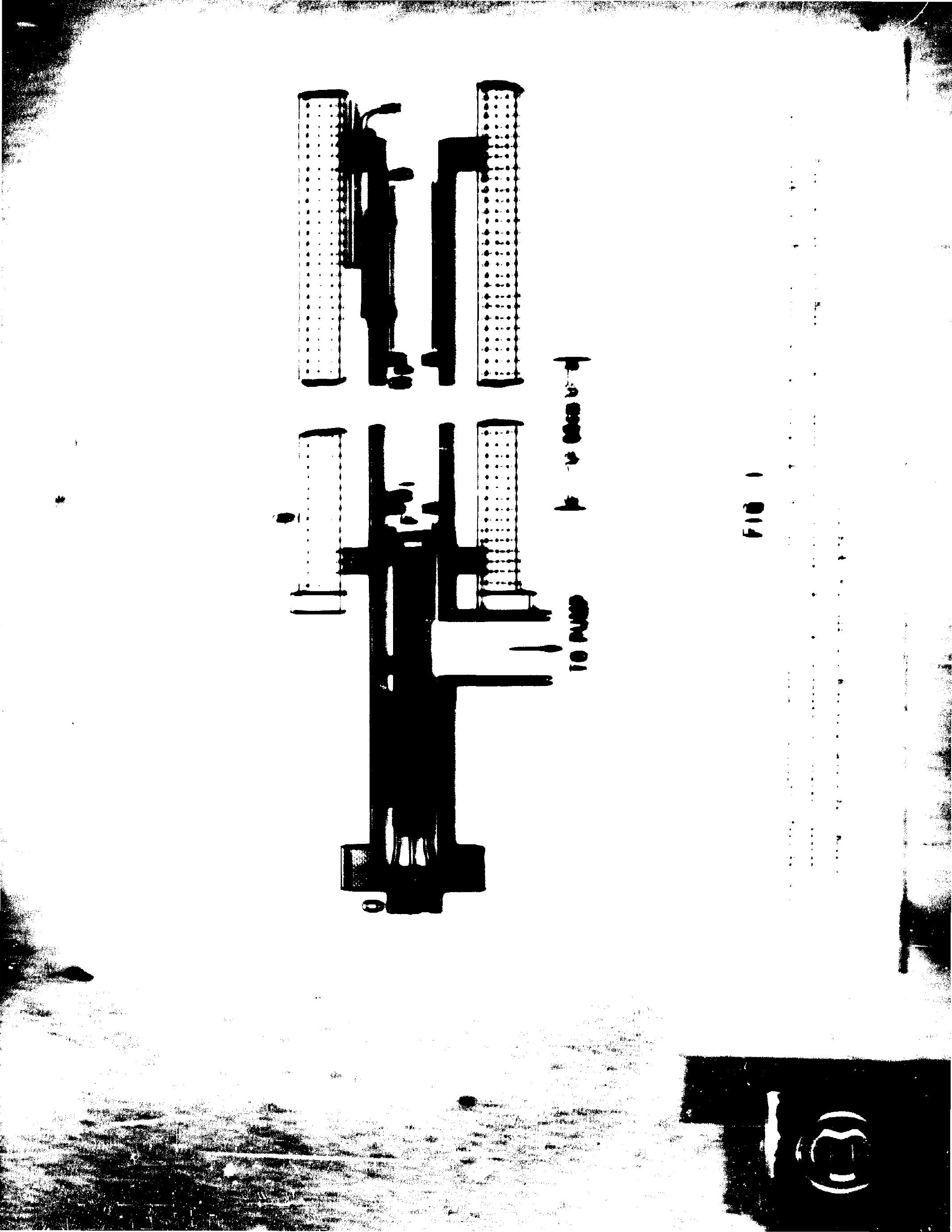




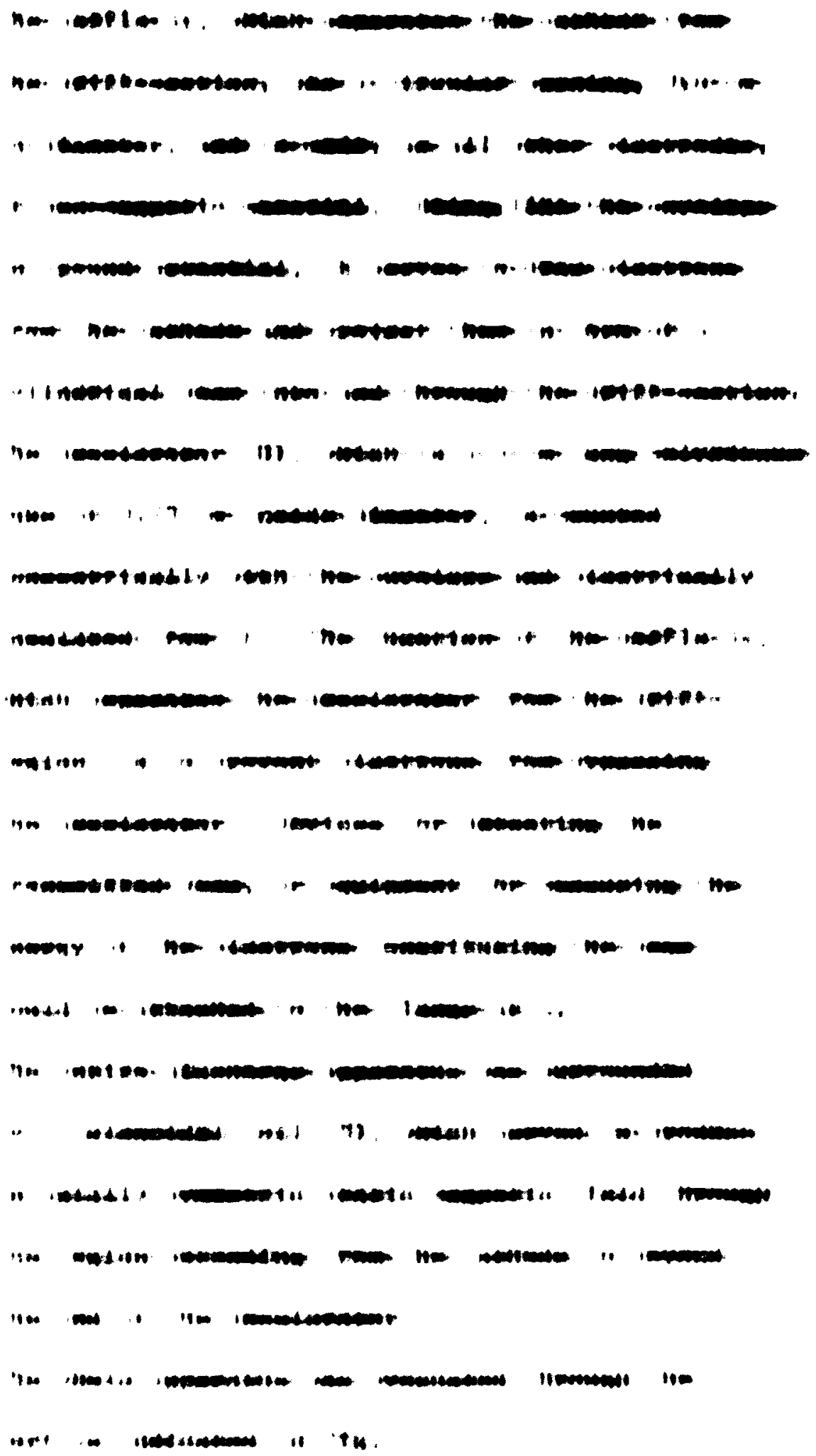




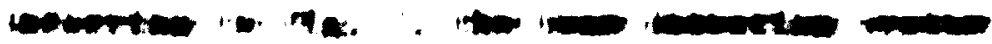

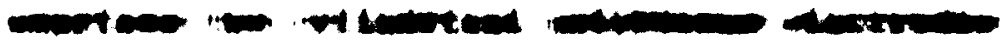




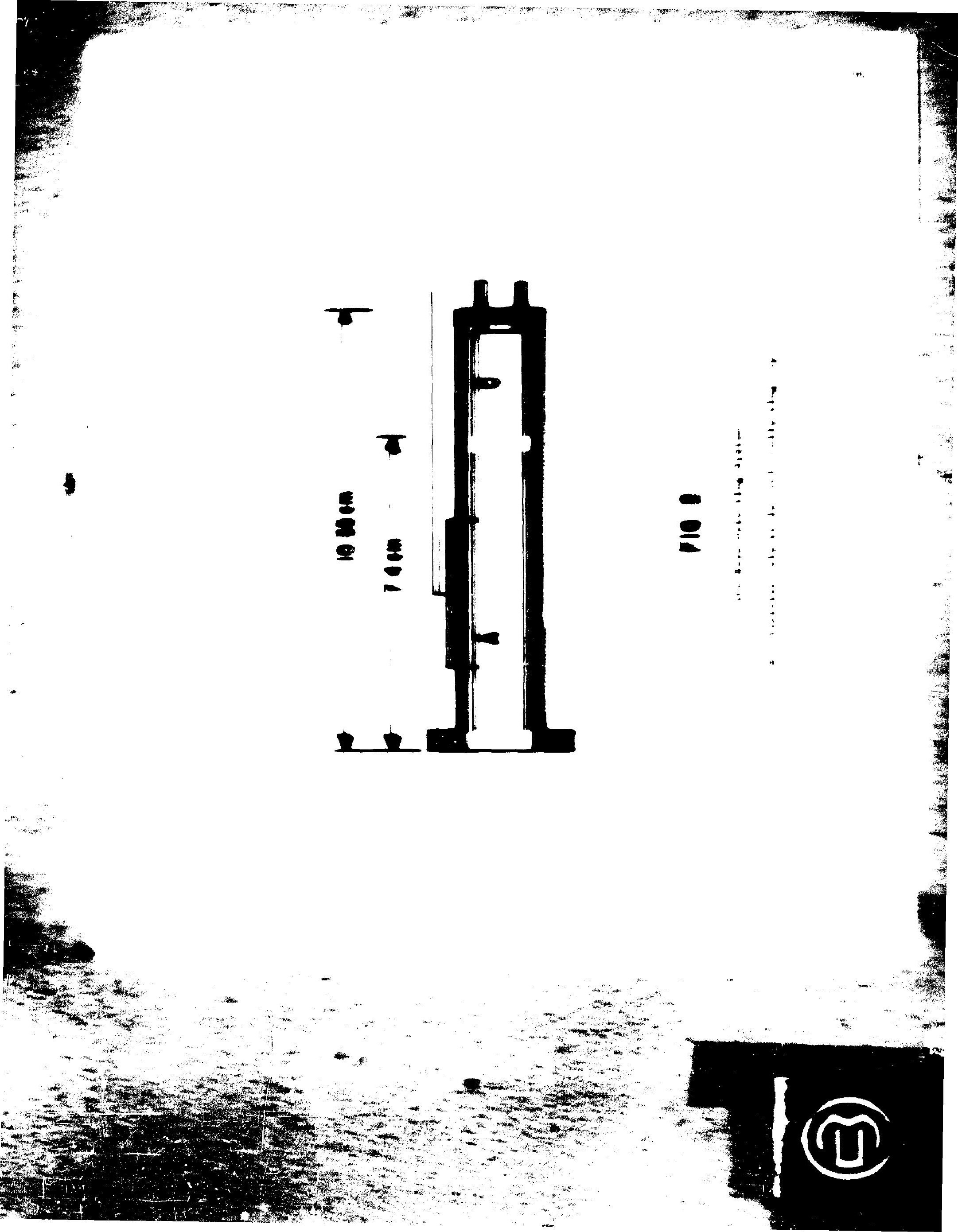




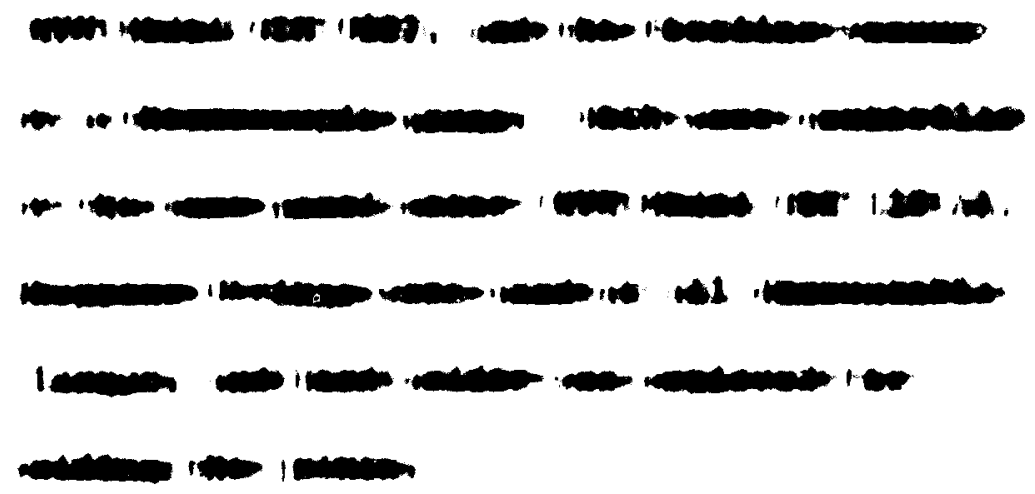




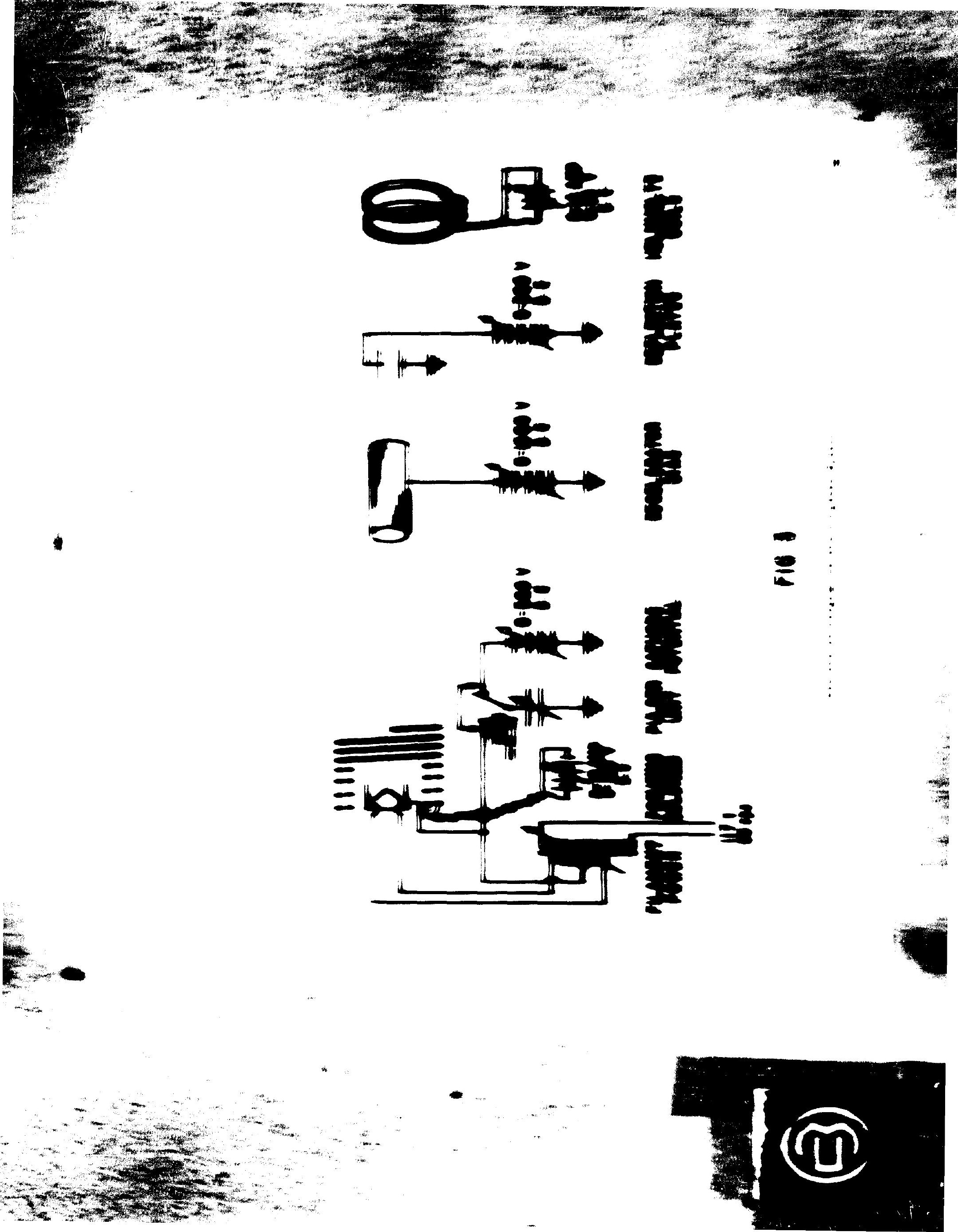




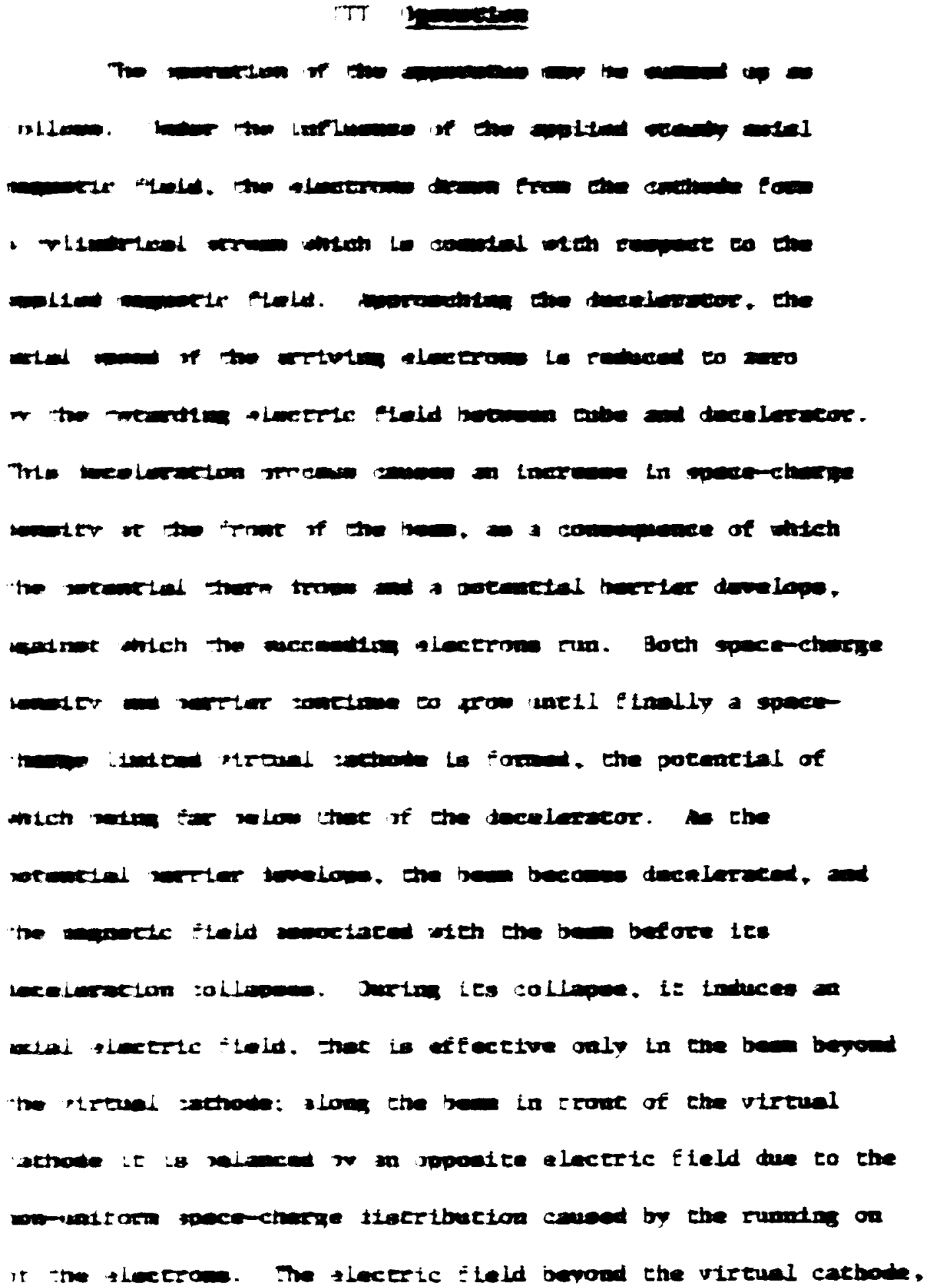


10.

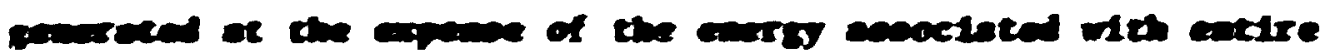

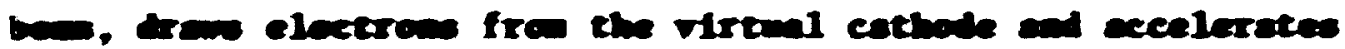

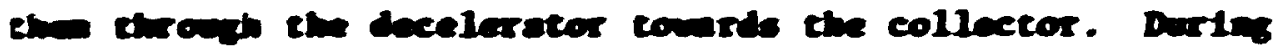
chis Hechurge procen, the virtwal cathole dioletegrates and the ben dipperwes onder the imf luesce of the radial interelectrondc forces. The weres then reform, and the whole procese is repented at a frepuency which depends on the operating condition.

The apparatus ang be considered to be the electrontc andoge to the bydravilc ran. It is, therefore, in the following frequently referred to as the "electrontc ran"; and the acceleration effect produced with this apparatus as the "ran effect". 
$\rightarrow \quad 3+i \sin x+x$

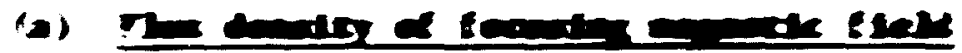

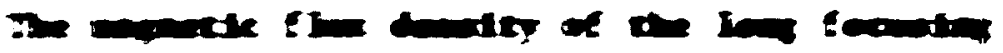

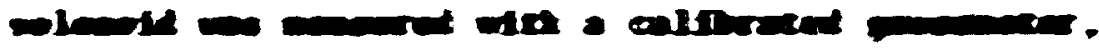

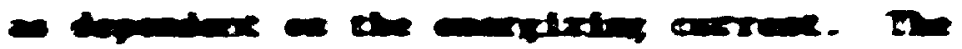

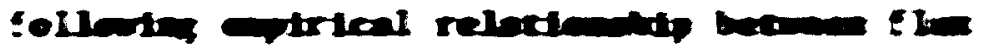

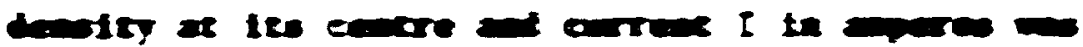

son :

$$
=45 \text { I }
$$

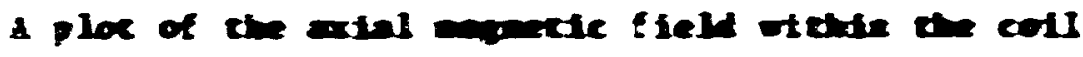

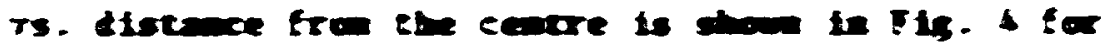

a constux currext of 3.7 aperes. Ihds we the

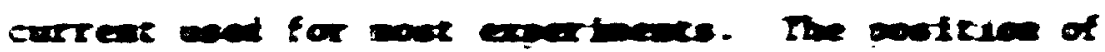

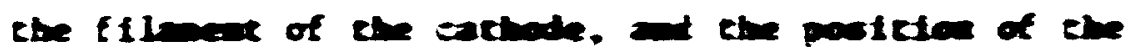
decelerator are alos inticated on the graph.

(b) Electron orree contarion

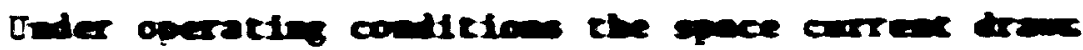

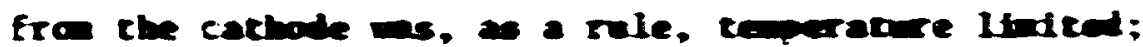
besce depentert on the filmext current only. For exple, at an acceleratifs roltage of 300 volts, the

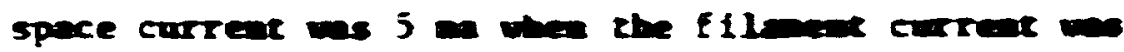
3.8 aps, and $10 \mathrm{~m}$, wher the fillowe curted

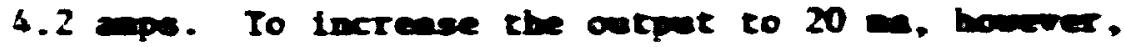




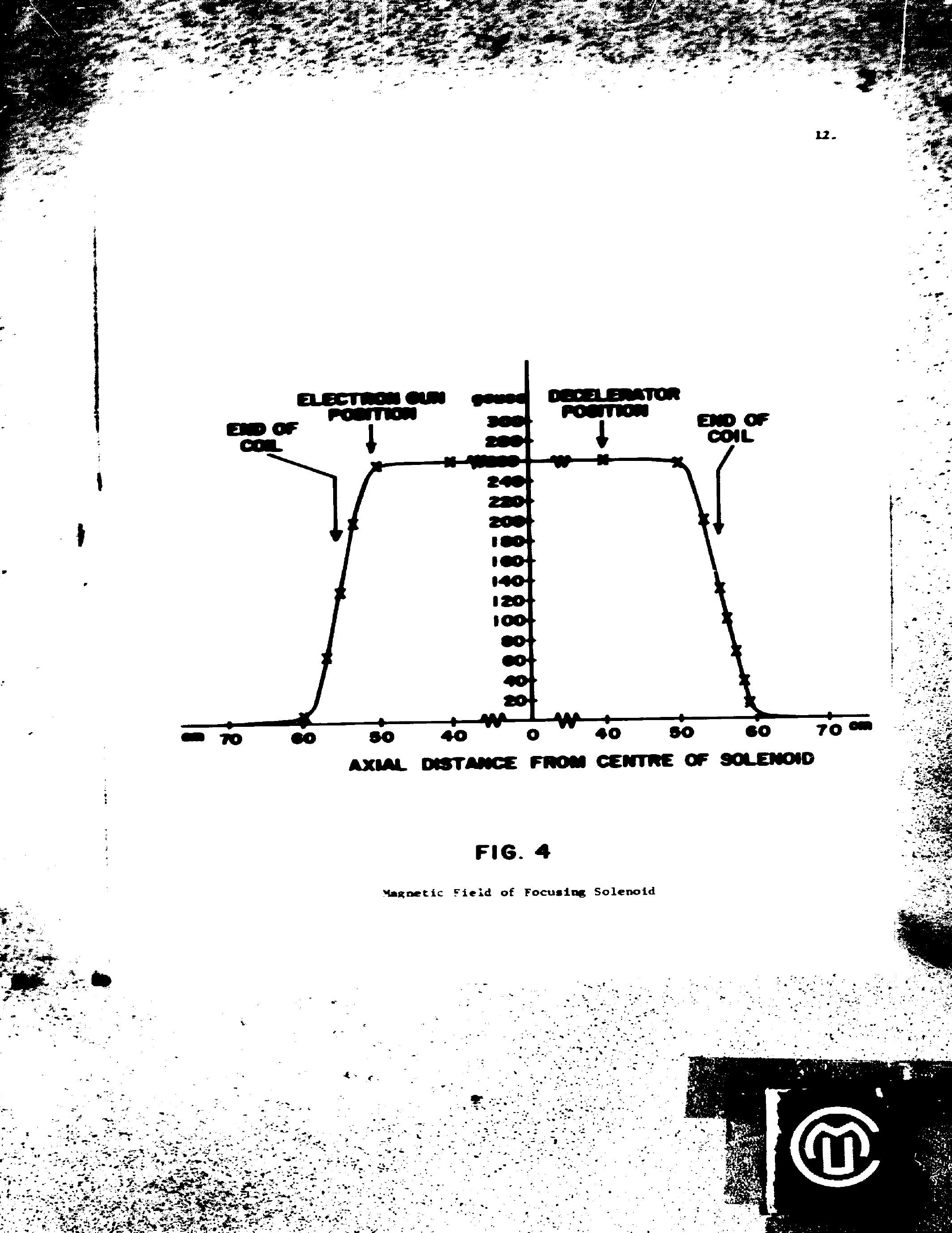


the sccelarating voltege had to be rated to

400 volte, and the f11mant curreat to 4.6 ape.

To mance the current digtribution to the various

electrodes in the dischrige derice, the bea

detecting equipant was jolned to flange X (PIg. 1).

The focusing angetic field was adfusted to 260 gause,

the opace current to 10 an at accelerating voltage

of 300 volts. The collector, aurillary electrode and

decelerator were grounded via aneters. Under these

condition, the current to the collector was found

to be $7.5 \mathrm{ma}$, and that to the auxiliary electrode

$0.3 \mathrm{ma}$. The current lajding on the decelerator

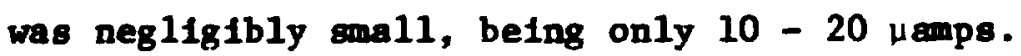

The baffles thus intercept about $22 \%$ of the total

em1ssion current.

(c) Output pulse with grounded decelerator

Fig. 5 shows an oscillogram of an output pulse which

was obtained with a Tektronix oscilloscope, Model 543 A,

when the cathode was pulsed. The pulsing capacitor

of $0.0047 \mu \mathrm{fd}$ was charged to -300 volts and intermittently

connected to the cathode. The filament current was

adjusted so that the peak beam current was $10 \mathrm{ma}$.

The decelerator was on ground, and the focusing

fleld 260 gauss. The collector which recelved the

current pulse was connected to the osc1lloscope

via shielded cable. In the photograph, the horizontal 


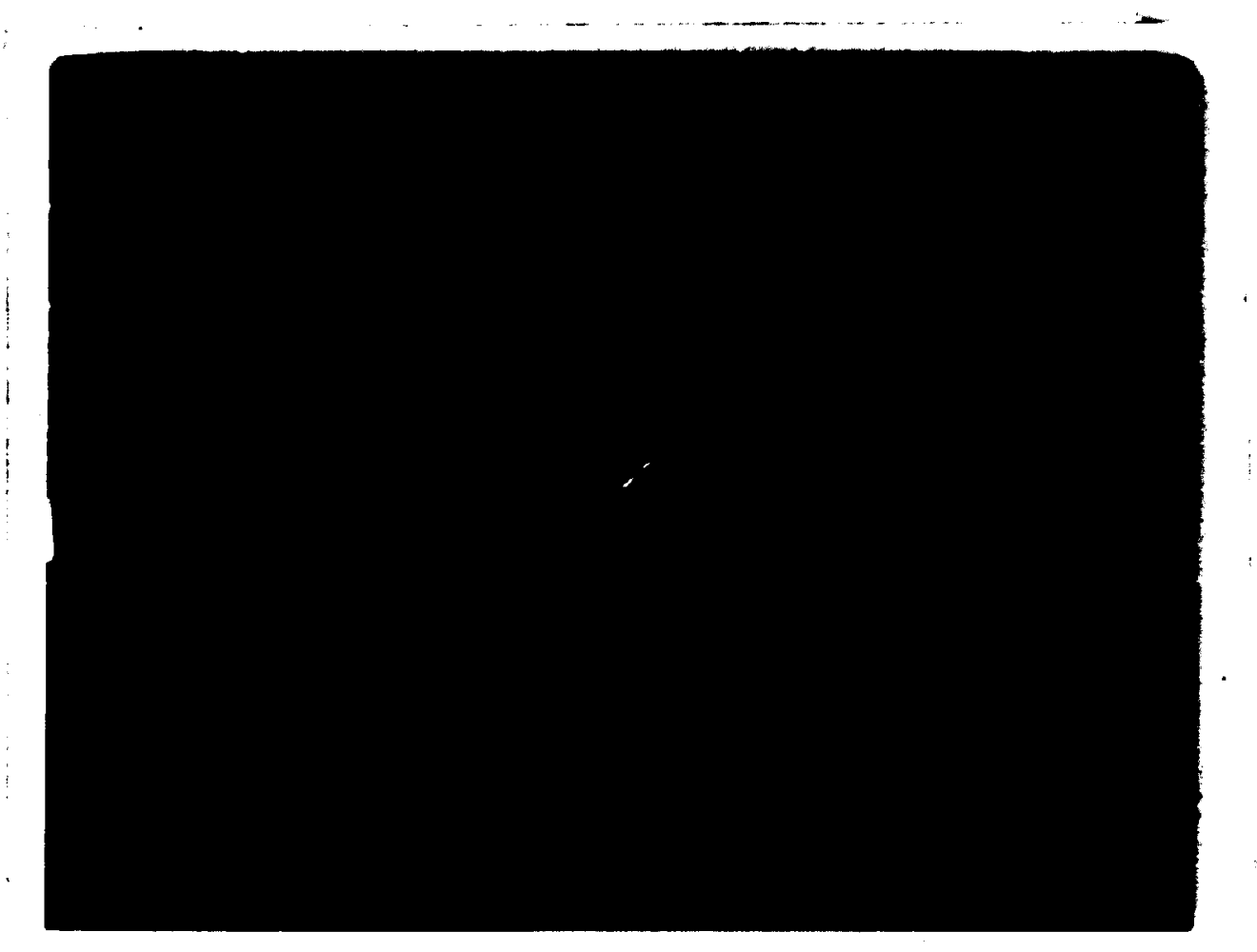

PIG. 5

Output Pulse W1thout Ran Rffect

Output acrose 10 megoh, deceloretor on ground, cathode Internittently on $-300 \mathrm{v}$, bese current $I_{b}=10 \mathrm{ma}$, focusing field B $=260$ gause, tine seele 0.5 usec/cm, eansitivity $2 \mathrm{v} / \mathrm{cm}$, sigle weep, tine increasen to right. 


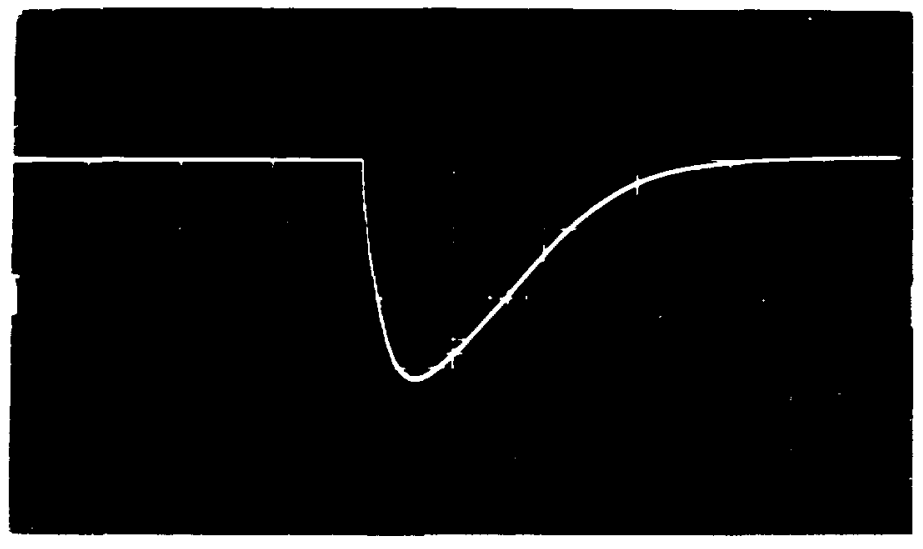


seale to 0.5 ailliseconde/ $c$, the vertical scale $2 \mathrm{volts} / \mathrm{cm}$. Tine increases to the right.

The total capacitance of the collector system, Including the input capacitance of the osc11loscope 1821 picofarads, which 18 shunted by a 10 megohm resistance to ground. The pulse observed on the oscilloscope, hence depicts the voltage to which this capacitance was charged up by the electron current. The rounded top, which is due to the tall portion of the electron beam, is followed by the exponential decay of the voltage on the output capacitance. The pulse is negative, Indicating an electronic current.

(d) Output pulses with negatively biased decelerator Before proceeding to the description of the actual energy measurements, it w111 be shown what happens to the output pulse when the decelerator is not grounded but at a potential which is negative with respect to the cathode. The osc1llogram in Fig. 6, for instance, was obtained under the same conditions as that In Fig. 5, except that the decelerator was at a potential of -600 volts with respect to ground. As distinct from the exponential decay of the output voltage, the trace of the pulse rise is Invisible. Obviously the writing speed 


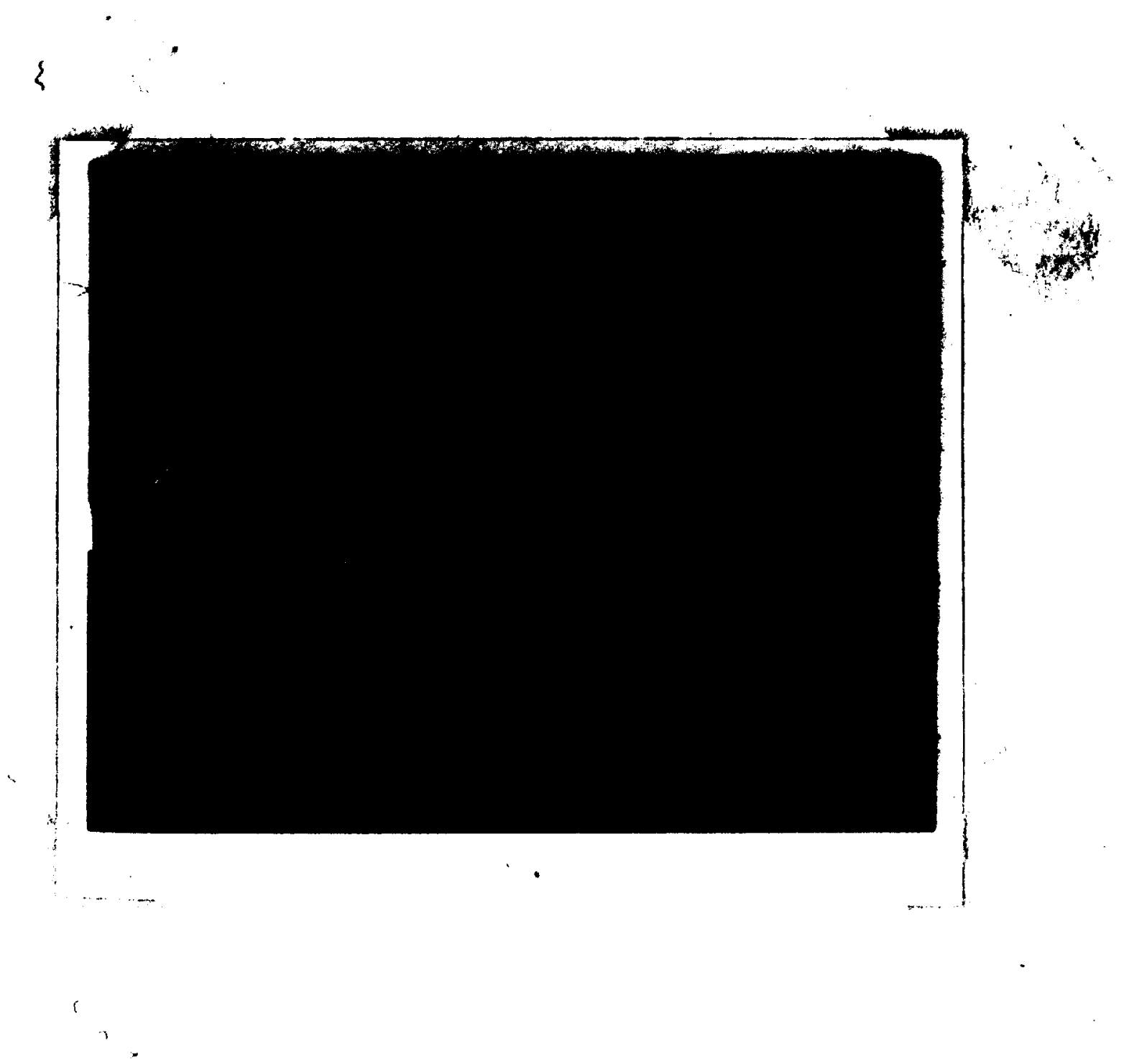

IIG. 6 (a)

Output Pulece With ron sffect

Output ecrose 10 megohn, decelezator on $-600 \mathrm{v}$, cathode 1nter-

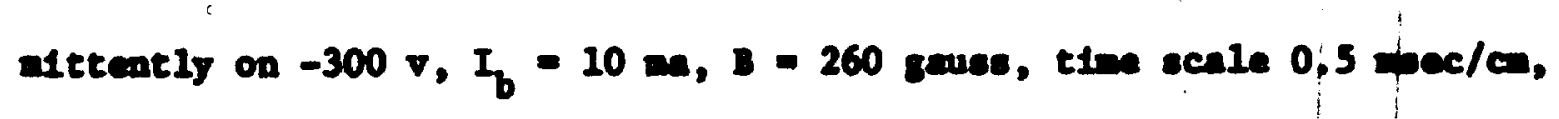
sensitivity $0.5 \mathrm{v} / \mathrm{cm}$, elogle sweep. 


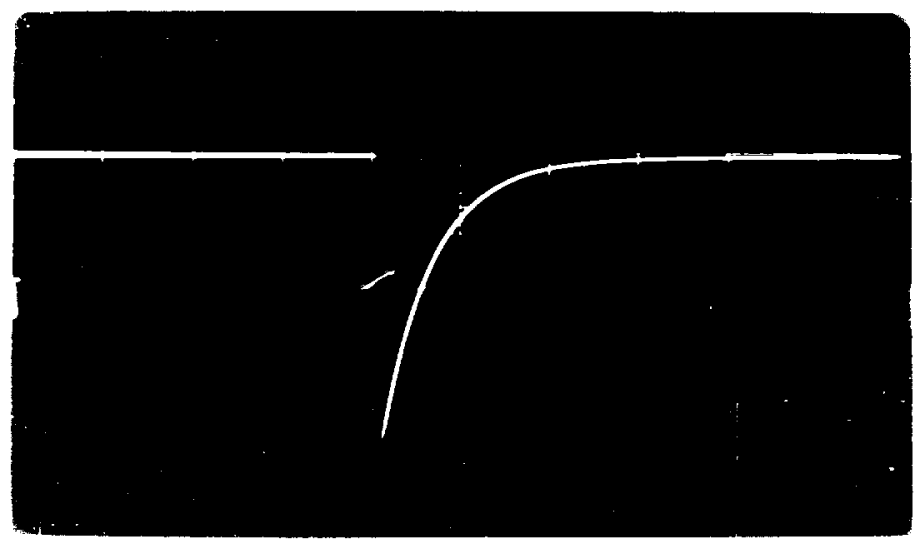




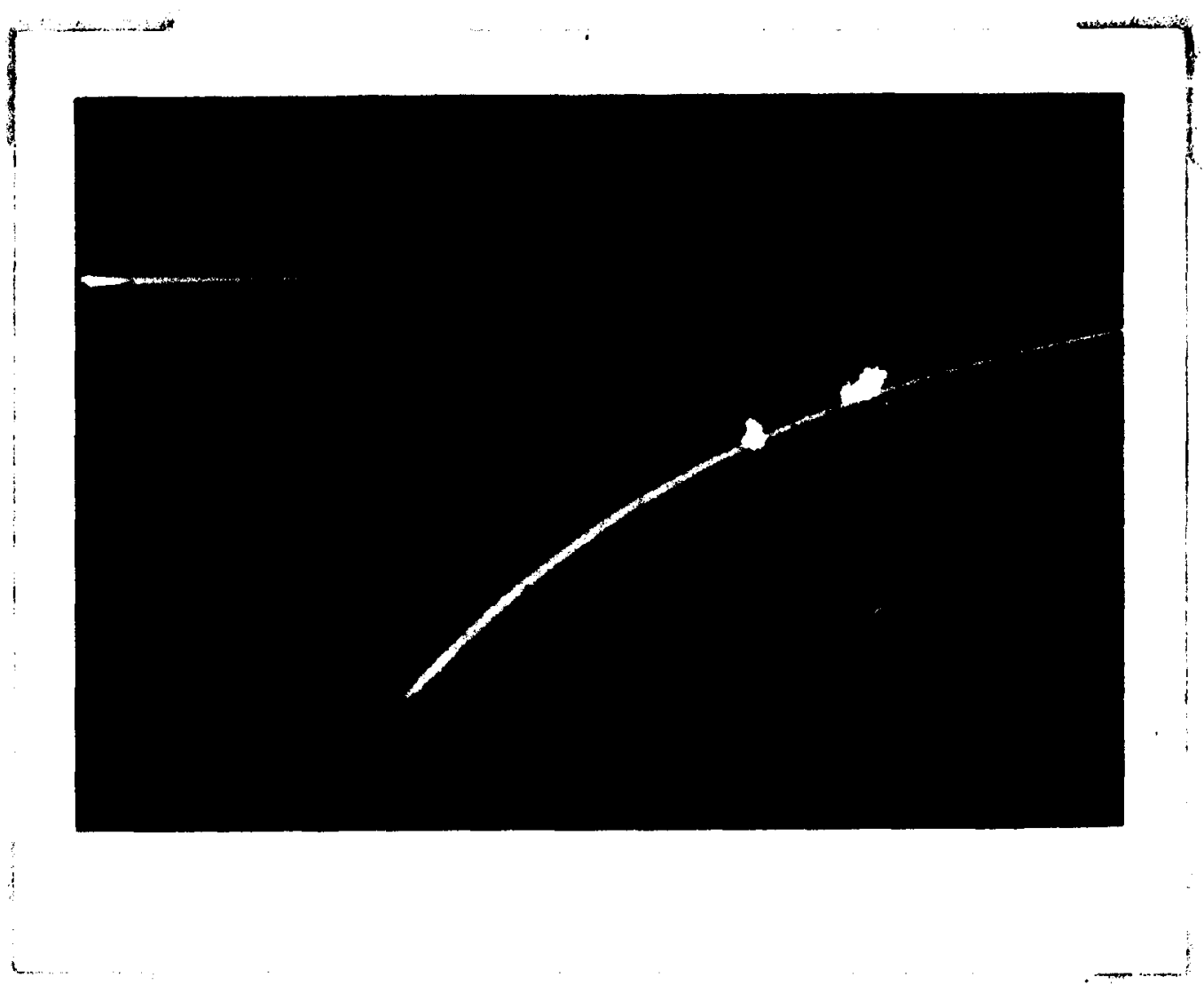

FIG. 6 (b)

Output Puleee With Re Effect

Same condittons as 6 (a), except time scale 100.05 meec/cm. 


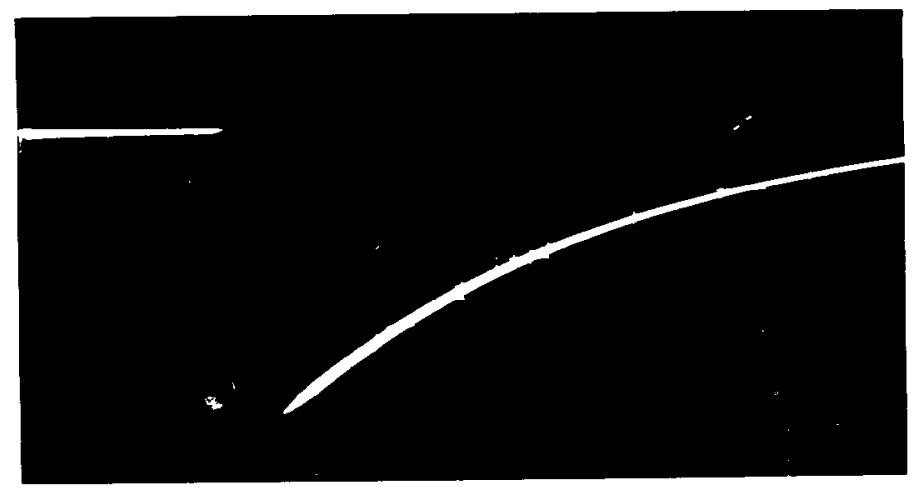

wow

$-1-1$ 

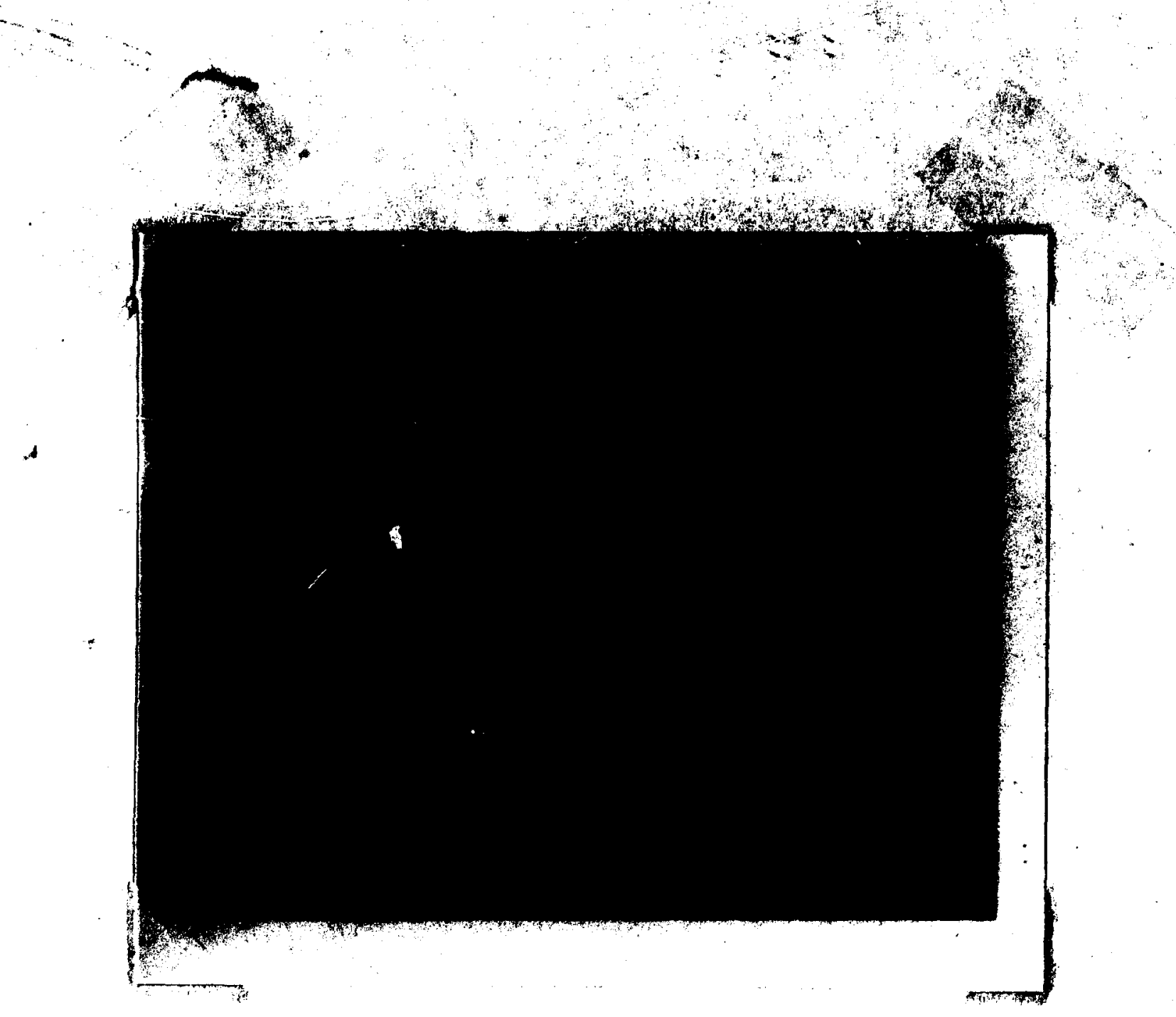

no. 6 (c)

Output Pulece W1th in Iffect

Output acrose 1 xohs, decelerator on $-600 \nabla$, cathode contimagaelp on $-300 \mathrm{v}, I_{b}=3 \mathrm{ma}, \mathrm{B}=260$ gawes, time scale $0.5 \mathrm{mecc} / \mathrm{cm}$, sonaltivity $0.05 \mathrm{v} / \mathrm{cm}$, elogle sweop. 


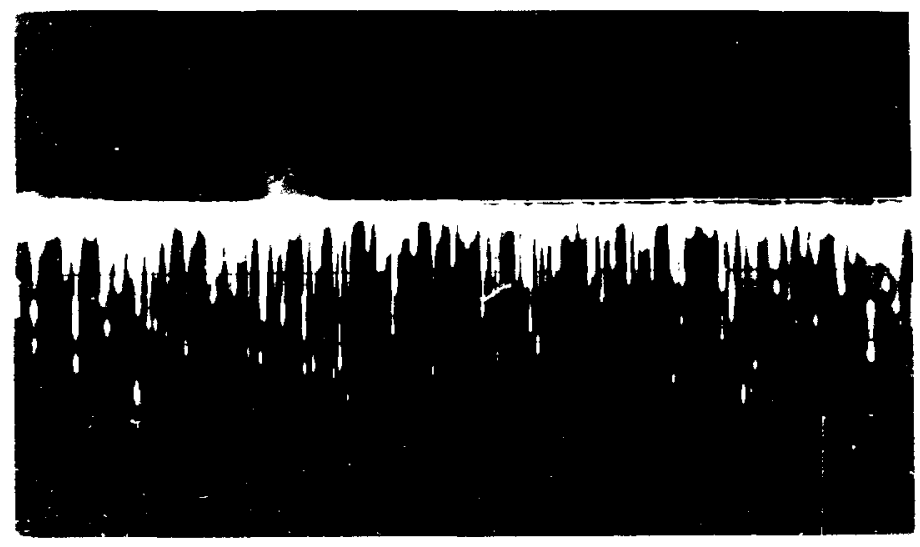

$-$ 
of the scope was too slow for the sudden rise. F1g. 6(b) shows a similar pulae, obtained under the same conditions, with expanded time base and higher writing Intensity of the ogcilloscope. F1g. 6(c) shows the output when the cathode is continuously operated. The beam current here was $3 \mathrm{ma}$, the cathode on -300 volts, the decelerator on -600 volts with respect to ground, and the focusing field was 260 gauss. The oscilloscope input In this case was shunted by a 1R $\Omega$ resistance, to reduce the time constant of the output circuit. Many small negative spikes were observed, each corresponding to an electron pulse. No satisfactory synchronization of the output pulses could be achieved to determine the "natural frequency" of the occurrence of the ram effect. 


\section{Energy Measurements and Results}

(a) Electric Deflection Method

Referring to $\mathrm{F} 1 \mathrm{~g}$. 7, if $\mathrm{A}$ is the point of entry of an electron of energy eV Into an electric field, its perpendicular deflection y after having travelled a distance $\left(L+\frac{1}{2}\right.$ l) is given by the famillar formula

$$
y=U \ell\left(L+\frac{1}{2} \ell\right) / 2 v d
$$

where $\mathrm{V}$ denotes the accelerating voltage

$U$ the deflecting voltage

$\ell$ the length of the deflecting plates $P$

$\mathrm{L}$ the distance between plates and collector C $y$ the perpendicular deflection from the axis Accordingly, a deflecting plate system was bullt; it is shown schematically in Fig. 8. When connected to flange $X$ in Fig. 1, with the beam detecting apparatus joined to flange $Y$ as shown in Fig. 8, the following quantities of Eq. (1) are geometrically fixed at the values:

$$
\begin{aligned}
\mathrm{d} & =0.64 \mathrm{~cm} \\
\ell & =2.46 \mathrm{~cm} \\
\left(L+\frac{1}{2} \ell\right) & =12.33 \mathrm{~cm} \\
y & =0.37 \mathrm{~cm}
\end{aligned}
$$


Substituting these values in (1), and solving for $V$,

$$
V=64 U
$$

is obtained for the energy of electrons that just miss the edge of the collector at a deflection voltage $\mathrm{U}$.

The baffles in front of and behind the deflecting plates have circular openings $0.5 \mathrm{~cm}$ in diameter, and the distance between the end of the decelerator and the first baffle $1819 \mathrm{~cm}$. The output current from the collector was measured with a sensitive electrometer (Kelthley Model 610 A). The auxiliary electrode was held at $+18 \mathrm{v}$ with respect to ground by a dry battery, to suppress the emission of secondary electrons by stray primaries.

Typical results of the deflecting plates measurements are pregented in Fig. 9 in form of a graph in which the collector current is plotted versus deflecting voltage for three different modes of operation. Curve (1) was obtalned without ram effect, $1 . e .$, with the decelerator on ground and the cathode on -900v; curve (2) with ram effect, i.e., decelerator on $-900 \mathrm{v}$ and the cathode intermittently on $-300 \mathrm{v}$ relative to ground at a rate of $60 \mathrm{cps}$; 


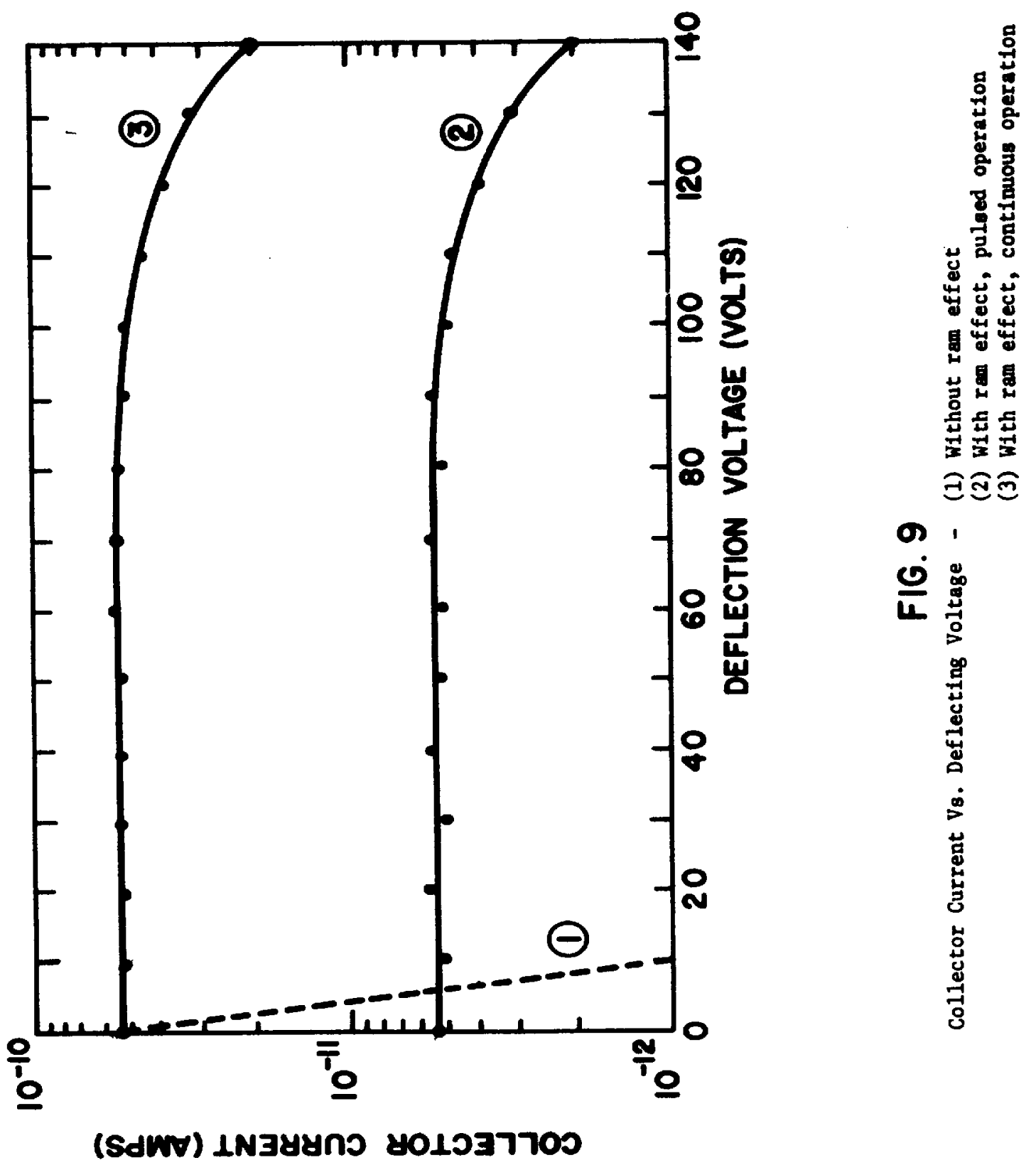


curve (3) under the same conditions as curve (2), except that the cathode was not pulsed but continuously operated. The larger output in this case is due to the higher repetition rate of the ram effect. For the operation without ram effect the filament current was adjugted to give at zero deflecting voltage the same reading as for the continuous operation with ram effect. Reversing the polarity of the voltages across the deflector plates did not appreciably change the results, which indicates that the beam was well centered.

Curve (1) shows that without ram effect the output current drops rapidly as the deflecting voltage Increases, being at $10 \mathrm{v}$ only $1 \%$ of 1 ts Initial value. Apparently the diameter of the beam was approximately equal to that of the circular hole in the baffles. The more the beam deviates from the axis the smaller the fraction of the beam that impinges on the collector. If the cross-section of the beam were negligibly small relative to that of the aperture of the baffle, the collector current would remain constant unt1l the voltage reaches the "cut-off" value at which the beam would just miss the collector. Theoretically, the value of the cut-off 
voltege for 900 v-electrons wo foum to be $14 \nabla$.

Table (1) gives reaults of deflection plate neasurenents under various operating conditione.

Here $I_{b}$ stands for been current, $E_{b}$ for been accelerating voltage, $B_{f}$ for focusing magnetic field and $E_{8}$ for beam-stopplng potential on the decelerator.

Table 1

Current recorded at collector as a function of deflecting voitage, under varlous operating conditions in units of $10^{-12}$ amps.

\begin{tabular}{rcccc}
\hline $\mathrm{U}$ & $\mathrm{b}$ & $\mathrm{c}$ & $\mathrm{d}$ & $\mathrm{e}$ \\
\hline 0 & 4.8 & 3.4 & 6.3 & $\mathbf{8 . 2}$ \\
10 & 4.9 & 3.5 & 6.0 & $\mathbf{8 . 0}$ \\
20 & 4.9 & 3.4 & 6.2 & 7.9 \\
30 & 4.7 & 3.2 & 6.0 & 7.8 \\
40 & 4.6 & 3.2 & 6.1 & 8.0 \\
50 & 4.6 & 3.4 & 6.0 & 7.7 \\
60 & 4.8 & 3.2 & 6.2 & 7.5 \\
70 & 4.9 & 3.6 & 6.1 & 7.5 \\
80 & 4.6 & 3.4 & 5.8 & 7.6 \\
90 & 4.4 & 3.5 & 5.5 & 7.2 \\
100 & 4.4 & 3.1 & 4.6 & 6.4 \\
110 & 3.6 & 3.1 & 3.8 & 5.7 \\
120 & 2.2 & 2.5 & 3.0 & 5.5 \\
130 & 1.8 & 2.3 & 2.1 & 4.7 \\
140 & 0.8 & 1.7 & 1.3 & 4.0 \\
\hline
\end{tabular}


(a)

(B)

(c)

(d)

(e)

\section{I}

$10=$

$10=$

$5=$

$10=$

$20=$

E

-300 -

-300 rolte

-300rolto

-300rolts

$-400 \mathrm{volts}$

$B_{f}$

260 anes

200gause

260gauss

260gause

260geves

B -900volts -900volts -900volts -450volts -600volts

(a) are the conditions of curve (2) Fig. 9.

(b) Magnetic Deflection Method

Suppose that, as shown in F18. 10, an electron moving along $A O$ meets at $O$ the boundary of a uniform magnetic field of flux density $B$ and direction perpendicular to axes $X$ and $Y$. Using mks units, the deflection y is given by

$$
y=\left(e x^{4} B^{2} / 8 m V\right)^{\frac{1}{2}}
$$

where $V$ is the accelerating voltage

$\frac{\mathrm{e}}{\mathrm{m}}$ the electronic charge to mass ratio

$x$ the distance traversed in $B$

$y$ the perpendicular deflection

$B$ the flux density

A beta-ray spectrometer was designed and built; as schematically shown in Fig. 11. The circular chamber was machined out of a solid piece of brass, the cylindrical cavity being $1.6 \mathrm{~cm}$ deep. It was sealed of $\mathrm{f}$ by means of a 
23.

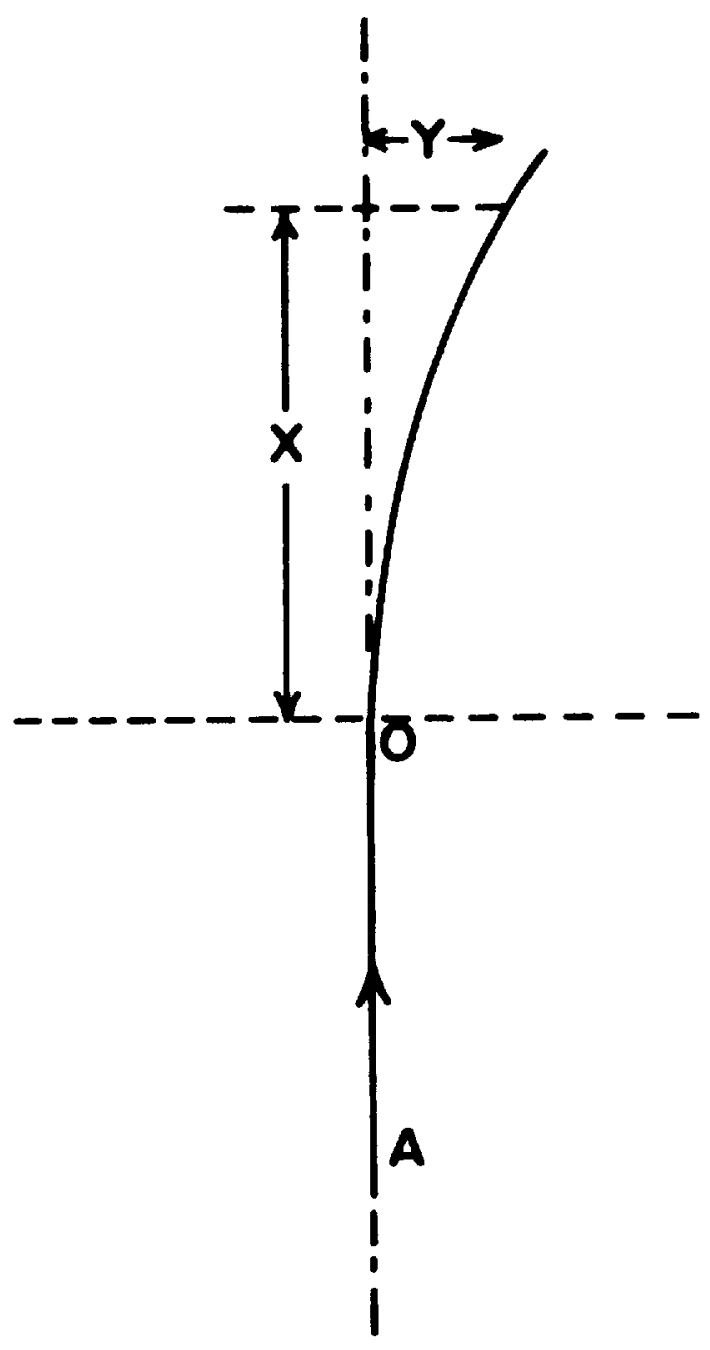

FIG. 10

Deflection by a Magnetic Field 


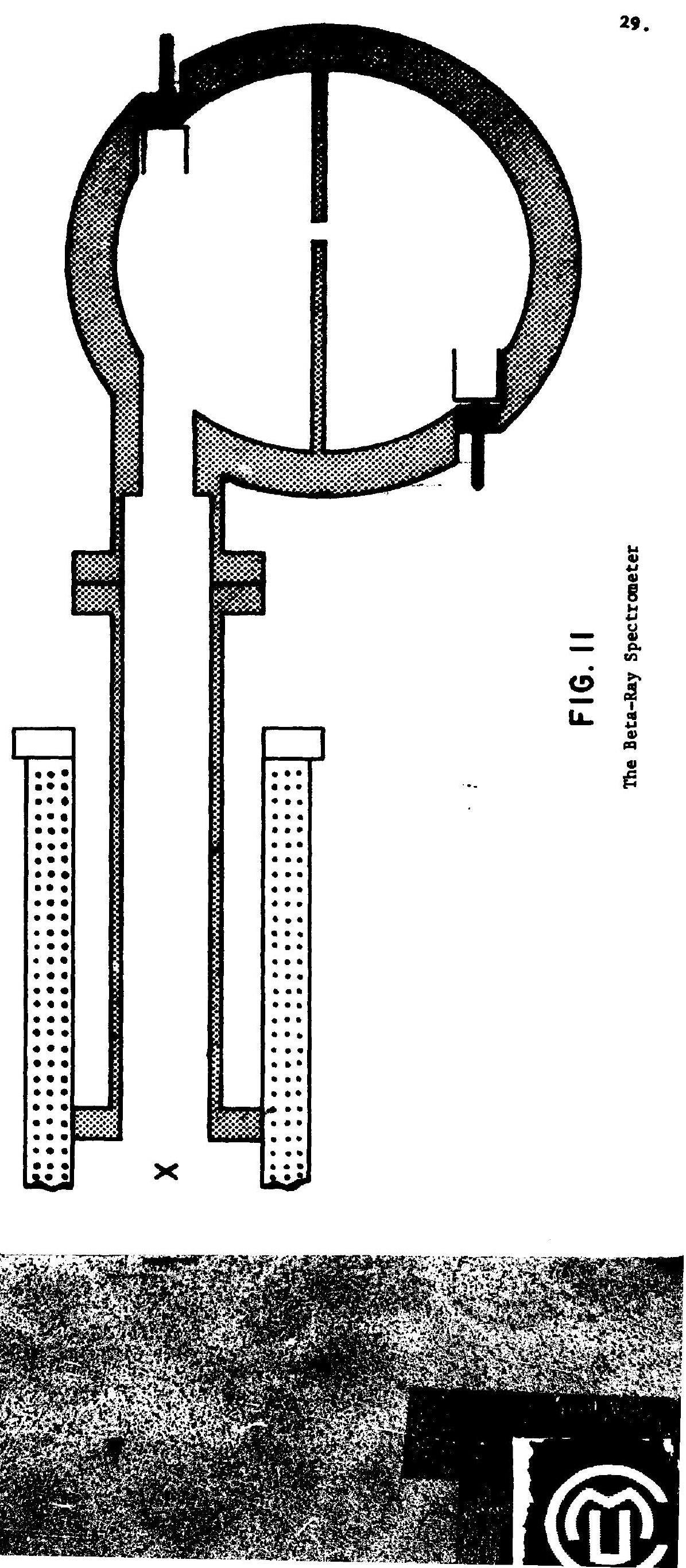


plexiglass plate and a wire mesh screen, to shleld the cavity from external fields. Two collecting electrodes and a slotted metallic partition are situated in the cavity. A set of specifically designed Helmholtz colls provided a reasonably uniform axial magnetic field. The flux density distribution is shown in Fig. 12. The Helmholtz coils could stand, for a short time a current of 14 amps; the experimentally determined relation between the coll current and the resulting average magnetic field over the electron path in gauss is

$$
B=6 I
$$

where I is in amperes. Originally it was intended to deflect the beam into a semicircular path through the slot to the lower collector, but the magnetic field proved to be too weak to accomplish this. Fig. 14 shows the complete experimental arrangement, with the beta-ray spectrometer attached. Substituting the geometrically fixed values of

$$
\begin{aligned}
& x=4 \times 10^{-2} \mathrm{~m} \\
& y=10^{-2} \mathrm{~m}
\end{aligned}
$$

and $\frac{e}{\mathrm{~m}}=1.76 \times 10^{11} \mathrm{coul} / \mathrm{kg}$

in Eq. (3), and using the relation (4), the energy V 


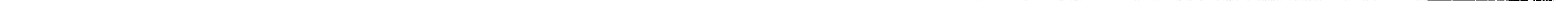




\section{of electron thet fort its the "1-110" \\ collectios enp is give by}

$$
\nabla=200 I^{2}
$$

The output current as a function of the coll current was Investigated under the sane operating conditions as the effect of the electric deflection. Typical results of these studies are again presented in form of a graph, In which the output current in amperes is plotted versus coll current in amperes. Curve (1) In F1g. 13 was obtained with the decelerator on ground and the cathode on $-900 \mathrm{v}$ relative to ground; 1.e., without ram effect; Curve (2) with the decelerator on $-900 \mathrm{v}$ and the cathode pulsed with $-300 \mathrm{v}$ relative to ground; Curve (3) under the same conditions as Curve (2), except that the cathode was continuously on $-300 \mathrm{v}$ with respect to ground.

Consistent with the deflection plate results, varying the operating parameters did not significantly affect the results obtained. In all experiments, whenever the electron beam was deflected in front of the decelerator by means of a permanent magnet, or the focusing fleld turned off, or the cathode 


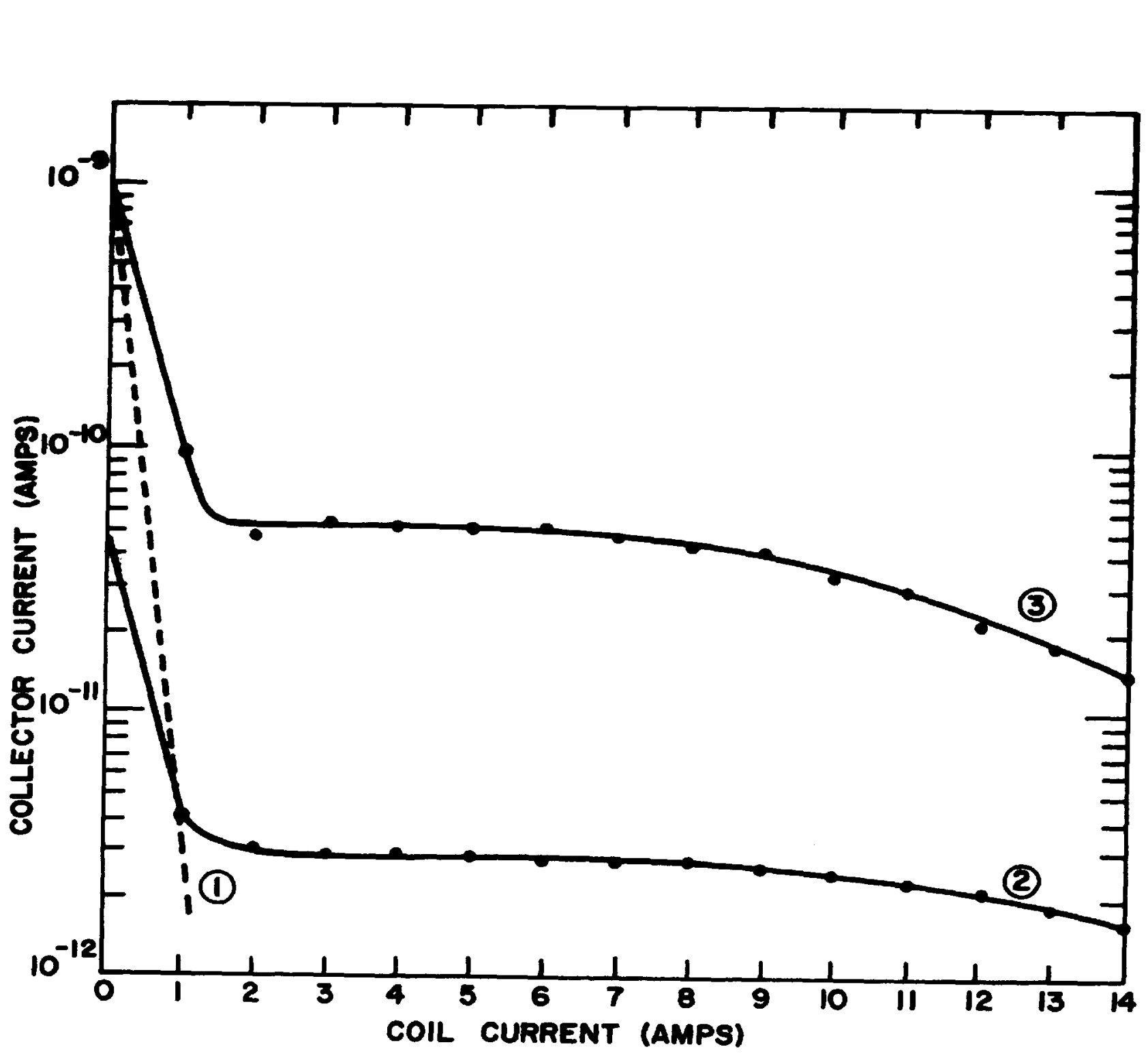

FIG. I3

Collector Current Vs. Current In Helmholtz Colls - (1) Without Ram Effect

(2) Wth Ram Effect, pulsed operation

(3) W1th Rem Effect, continuous operation.

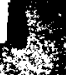

40

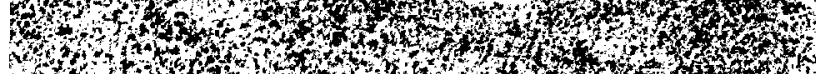

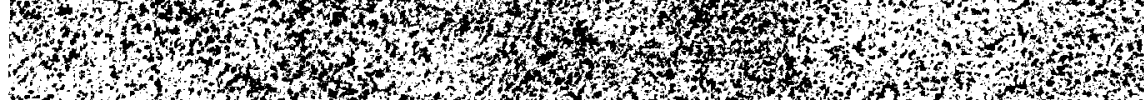

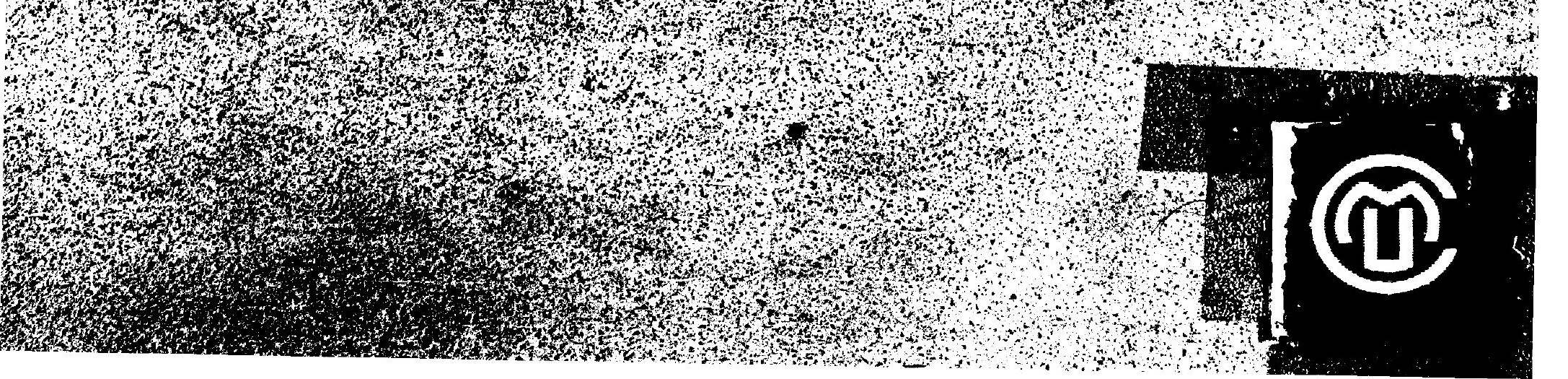


potential removed, or the f1lmeat current turned off, the output insariably dropped to zero. This proves that the observed output was entirely due to the tranonitted portion of the bean, and by no means caused by lonfzation or plck-up effects. 


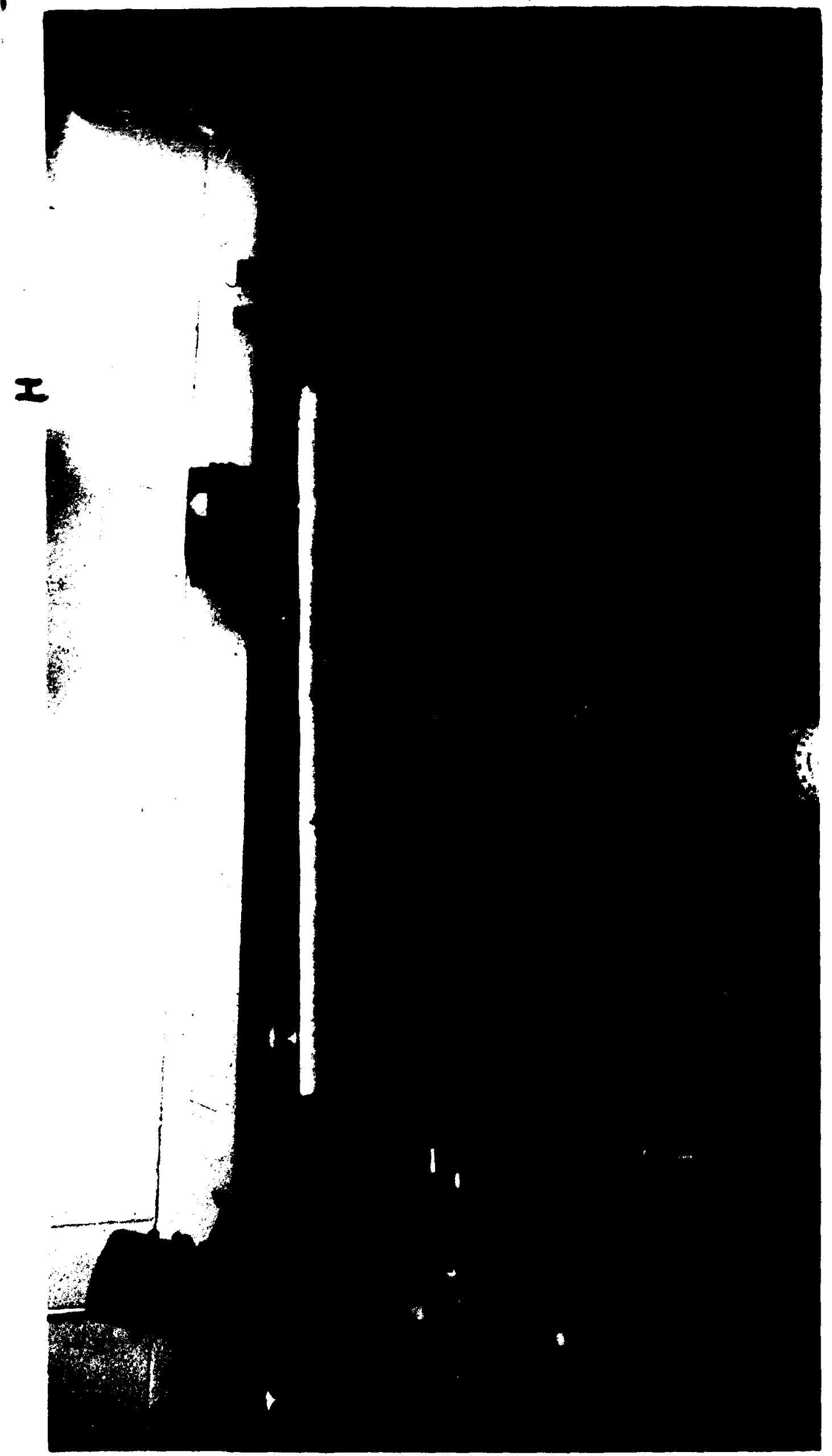




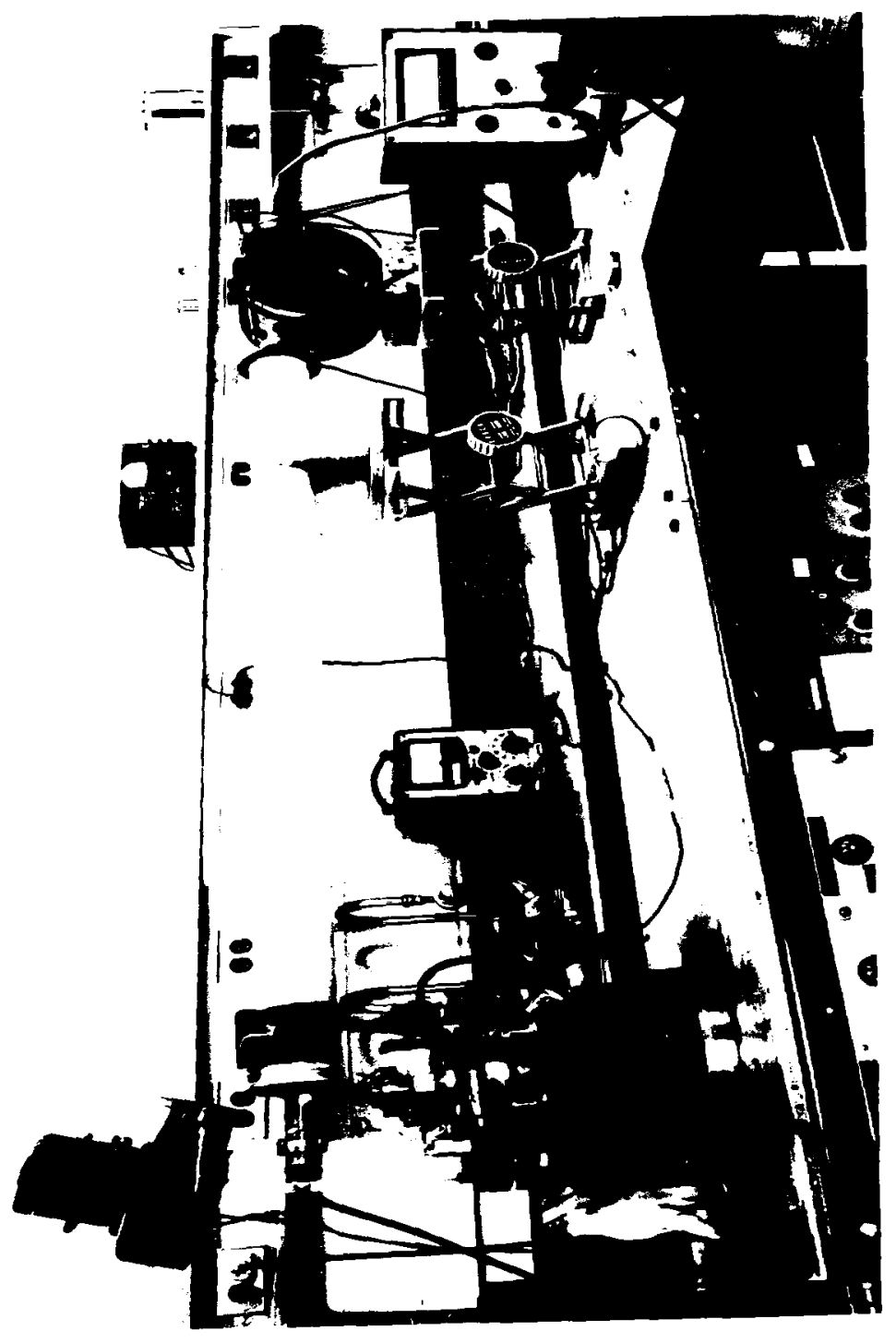

$-n$ How 


\section{Discussion of Results}

Comparing the shape of the output pulse in Fig. 5 with that of the output pulse in Fig. 6, one notices a drastic difference. This indicates that the discharge mechanism in the case of the negatively biased decelerator differs considerably from that with the decelerator grounded. Apart from the reduced size of the pulse in the second case due to the much smaller charge impinging on the collector, the rise of the pulse is almost instantaneous. Obviously, when the decelerator is negative with respect to the cathode, an acceleration effect occurs, which produces a burst of a small, extremely fast electronic charge.

Under continuous operation, as shown in Fig. 6(c), the ram effect takes place much more frequently, although somewhat erratically. This is not surprising in view of the inherent statistical character of the result of a collision between a beam of interacting electrons with a potential barrier. Successive beams cannot be expected to be Identical in every respect. Fluctuations in the beam structure are likely to affect the entire discharge process, including deceleration, dispersion and reformation of the beam. Frequently a reformed beam may not produce an output pulse at a11, e.g. when the cathode was intermittently operated, 
the frequency of the output pulses was always below that of the pulser. Although the time constant of the pulsing circuit was roughly 100 times larger than the transit time of the beam ( 0.1 usec at $300 \mathrm{eV})$, only on rare occasions was more than one output pulse per cycle of the pulser observed. Turning now to the evaluation of the actual energy measurements of the electrons constituting these pulses, Curve (2) of Fig. 9 shows that the current, plotted versus deflection plate voltage, remains constant at $5.2 \times 10^{-12}$ amps up to 100 volts. Only when the deflecting voltage exceeds 100 volts a decresse of output current sets in. Applying the relation for beam energy (3)

$$
\mathrm{V}=64 \mathrm{U}
$$

one obtains for $U=100$ volts an energy of $6.4 \mathrm{KeV}$ for the output electrons. Th1s, however, only represents the lowest energy in the output beam which passes through both deflection plate baffles. The current is far from being completely cut off at $U=140$ volts, It actually could still be detected at $U=300$ volts. Thus the electrons accelerated into the collector exhibit a spectrum of energies from $6.4 \mathrm{KeV}$ upward. Curve (3) shows the same behavior, only here the average current Is larger due to the more frequent occurrence of the accelerating effect. As can be seen from Curve (1), when a beam of $900 \mathrm{eV}$ energy is directed through the deflecting plates, it drops sharply, 
and is completely cut off at $U=15$ volts. The theoretical cut-off value is $U=14$ volts. Referring to Table 1, varlations of the operating parameters does not appreciably affect the results.

From Fig. 13, it is seen that curves (2) and (3) do not differ qualitatively. However, the presence of a soft component appears in the output, namely electrons which seem to have an energy of about $900 \mathrm{eV}$. These electrons were not discovered In the deflection plate measurements because of the use of baffles. Their energy indicates that they essentially accelerated by traversing the voltage between decelerator and envelope. Consequently, they are eliminated from the output beam at a coll current of 2 amps.

The straight portion of the graph now allows an easy determination of the minimum energy of the electrons. Making use of the energy-coil current relation (5)

$$
V=200 I^{2}
$$

and inspecting the graphs, one finds an energy of $7.2 \mathrm{KeV}$ for a coil current of 6 amps, at which value the output current begins to decrease. This energy agrees very well with the value found by the electrostatic deflection measurements.

Curve (1) again depicts the behavior of $900 \mathrm{eV}$ electrons. The current drops sharply with increasing magnetic fleld, and 
18 completely cut off at a coll current of 2 amps.

It is Interesting to calculate the average energy of the electrons in the output pulse. With a few simplifying assumptions and the aid of the oscillograms one can estimate the average output as follows. The energy invested in the initial beam is given by

$$
W_{b}=E_{b} q=E_{b} I_{b} t
$$

where $E_{b}$ is the accelerating voltage, $q$ the total beam charge which is equal to the product of $I_{b}$, the beam current, and $t$, the transit time. The energy of the output charge $\Delta \mathrm{q}$ is

$$
W_{0}=\frac{1}{2} \Delta \mathbf{q} \bar{v}
$$

where $\bar{v}$ is the average energy level of the output electrons. Assuming a $100 \%$ energy transfer from the input beam to the output beam

$$
\begin{gathered}
W_{0}=W_{b} \\
E_{b} q=\frac{1}{2} \Delta q \bar{V}
\end{gathered}
$$

and

$$
\bar{v}=2 E_{b} I_{b} t / \Delta q
$$


From the osc1llograms in FIg. 6(a), the output capacitance of $21 \mu \mu f$ is found to be charged up to 2 volts. This gives a value for $\Delta q$ of $4.2 \times 10^{-11}$ coulombs. The beam current $I_{b}$ In this case was $10 \mathrm{ma}$, the accelerating voltage 300 volts and the transit time was 0.1 usec. Substituting these values in $\mathrm{Eq}$. (6), the average energy in eV is $\overline{\mathrm{V}}=15 \mathrm{KeV}$, which In view of the assumptions is in reasonable agreement with the experimental values. 


\section{Conclusion}

The main purpose of this work was to demonstrate that a transfer of the energy of an advancing electron beam to the electrons at the front of the beam occurs upon collision of the beam with a potentlal barrler whose helght exceeds the energy of the electrons in the beam. To study in detall this energy transfer, further experimentation will be necessary with discharge devices which permit independent variation of the operation parameters. 


\section{Reference}

(1) Raudorf, W.R., Wireless Engineer, 28 (1951) 215-221. 